\title{
Multiparametric analysis of anti-proliferative and apoptotic effects of gold nanoprisms on mouse and human primary and transformed cells, biodistribution and toxicity in vivo
}

Marta Pérez-Hernández ${ }^{1,2^{*}}$ (D), María Moros ${ }^{3,4}$, Grazyna Stepien ${ }^{5,6}$, Pablo del Pino ${ }^{3,7}$, Sebastián Menao ${ }^{8}$, Marcelo de las Heras ${ }^{9}$, Maykel Arias ${ }^{2}$, Scott G. Mitchell ${ }^{10}$, Beatriz Pelaz ${ }^{3,7}$, Eva M. Gálvez ${ }^{11}$,

Jesús M. de la Fuente ${ }^{10,6}$ and Julián Pardo 2,3,12,13

\begin{abstract}
Background: The special physicochemical properties of gold nanoprisms make them very useful for biomedical applications including biosensing and cancer therapy. However, it is not clear how gold nanoprisms may affect cellular physiology including viability and other critical functions. We report a multiparametric investigation on the impact of gold-nanoprisms on mice and human, transformed and primary cells as well as tissue distribution and toxicity in vivo after parental injection.
\end{abstract}

Methods: Cellular uptake of the gold-nanoprisms (NPRs) and the most crucial parameters of cell fitness such as generation of reactive oxygen species (ROS), mitochondria membrane potential, cell morphology and apoptosis were systematically assayed in cells. Organ distribution and toxicity including inflammatory response were analysed in vivo in mice at 3 days or 4 months after parental administration.

Results: Internalized gold-nanoprisms have a significant impact in cell morphology, mitochondrial function and ROS production, which however do not affect the potential of cells to proliferate and form colonies. In vivo NPRs were only detected in spleen and liver at 3 days and 4 months after administration, which correlated with some changes in tissue architecture. However, the main serum biochemical markers of organ damage and inflammation (TNFa and IFNY) remained unaltered even after 4 months. In addition, animals did not show any macroscopic sign of toxicity and remained healthy during all the study period.

Conclusion: Our data indicate that these gold-nanoprisms are neither cytotoxic nor cytostatic in transformed and primary cells, and suggest that extensive parameters should be analysed in different cell types to draw useful conclusions on nanomaterials safety. Moreover, although there is a tendency for the NPRs to accumulate in liver and spleen, there is no observable negative impact on animal health.

Keywords: Gold nanoprisms, Nanotoxicology, ROS generation, Mitochondrial membrane-potential, Biodistribution, In vivo

\footnotetext{
* Correspondence: martaperezh@gmail.com

'Departamento de Bioquímica y Biología Molecular y Celular, Facultad de

Ciencias, Universidad de Zaragoza, 50009 Zaragoza, Spain

${ }^{2}$ Instituto de Investigación Sanitaria de Aragón (IIS Aragón), Centro de

Investigación Biomédica de Aragón (CIBA), Universidad de Zaragoza, 50009

Zaragoza, Spain

Full list of author information is available at the end of the article
} 


\section{Background}

The intrinsic optical properties of metal nanoparticles render them as versatile tools for a variety of bioapplications including, but not limited to, imaging, therapy and diagnosis [1-4]. In particular, anisotropic gold nanoparticles (NPs) such as nanorods [5], nanoshells [6], or nanoprisms $[7,8]$ show great promise for in vivo applications [5, 9-12]. Three main facts support the use of anisotropic gold NPs. First, the optical activity of these materials can be tuned along the NIR range, in the socalled biological window where absorption by physiological components is less restrictive [13]. Second, in contrast to other metal NPs made of silver or copper, gold is more noble and is considered one of the biologically safest element [11]. And finally, the abundance of synthetic approaches currently available offers researchers the possibility of engineering the size, shape and surface of these materials, enabling tailoring for specific purposes [11, 14].

In parallel to investigations concerning the development of new nanomaterials with optimal bio-performance (i.e. stability and performance for working in complex biological scenarios), testing the interactions of these materials with the living world has become a major issue for the successful development of bio-nanotechnology $[12,15]$. Past, present and future data concerning the impact of nanomaterials on biological systems will greatly influence the future roadmap of nanomaterials for bioapplications [16]. Materials aimed for bioapplications should preserve their original physicochemical properties in physiological conditions, but should also avoid impairing or compromising the proper function of biological entities such as proteins and cells. Nanotoxicology is a rapidly growing area, which is devoted to investigate such nano-bio interactions [17, 18]. Typically, the physicochemical properties of NPs including composition (inorganic core and surface coating), size, shape, crystallinity, and hydrophobicity can be correlated with their toxicity in vitro, which however can also vary among distinct cell lines and/or dose [14]. Yet no matter which NP model is being assayed, there are some common adverse effects [19] which can be triggered by the intrinsic dimensions of the NP under study [20]. Upon exposure to NPs the most common cellular response involves the generation of ROS, which can be tolerated up to certain levels without side effects, typically depending on the cell type $[19,21]$. In addition, alteration of the cellular homeostasis due to massive accumulation of NPs inside cells or interaction with signalling pathways can lead to a multitude of adverse effects $[19,22]$. It therefore stands to reason that choosing the most appropriate components and dose might prevent to some extent an adverse impact on cells. Toxicity issues triggered by release of toxic ions from metallic NPs composed of $\mathrm{Ag}$ [23] and $\mathrm{Cu}$, or QDs containing $\mathrm{Cd}$, are well documented in the literature [14]. In contrast, gold NPs coated with densely packed thiolated chains of polyethylene glycol (PEG), as used here, are believed to be among the safest NPs $[24,25]$.

Regarding near infrared (NIR) -active plasmonic materials, the toxicity of gold nanorods and nanoshells has been widely studied in vitro and in vivo and photothermal therapy using these materials is already in phase 1 clinical trials for the treatment of different cancer types (see details for AuroLase ${ }^{\circ}$ Therapy) [26]. In contrast, the impact of gold NPRs on cell cultures has yet to be investigated or characterized in detail, a prerequisite before analysing its safety and potential applications in in vivo models. The molar extinction coefficient of gold NPRs can be considerably larger to those of nanorods or nanoshells, [27] and therefore the interaction with incident light can be more efficient, leading to positive effects for various bioapplications such as photothermal therapy [7, 8], optoacoustic imaging [28], or plasmonic driven thermal biosensing $[13,29]$.

We have recently used different types of NPs to analyse the influence of shape on the interaction between NPs and cells and provide preliminary data on the potential toxic effects in vitro [20]. As a continuation of that work here we have focused on gold NPRs to perform a more extensive and detailed study of its effect on several common cellular parameters including ROS generation, mitochondria membrane potential, proliferation, cell morphology and apoptosis, employing a variety of cell models and two primary cell lines. Moreover, we have monitored tissue distribution and the main serum biomarkers of organ damage and inflammatory response in a mouse model in vivo in order to analyze the potential adverse effects of employing NPRs as carriers in theragnostic applications.

\section{Results}

\section{Characterization of NPRs}

NPRs are thin (ca. $10 \mathrm{~nm}$ ), flat single crystals, which present three congruent edge lengths of ca. $150 \mathrm{~nm}$ (Additional file 1: Figure S1). The surface of the NPRs was saturated with heterofunctional PEG chains (thiolPEG-carboxy, $5 \mathrm{kDa}$ ). PEGylation was achieved by using heterofunctional PEG chains (HS-PEG-COOH), which bind covalently to the gold surface through its thiol group. The carboxylic end group was used for further surface functionalization with 4-aminophenyl- $\beta$-D-glucopyranoside and/or a fluorescence reporter, 5-TAMRA cadaverine (an amine-modified rhodamine) using a carbodiimide crosslinker (more details in the materials section) (Additional file 1: Figure S2 and S3). Functionalization of NPs with glucose enhances both selectivity and uptake 
by target cells [20]. The rhodamine dye, TAMRA, was used as a fluorescent marker to facilitate the localization of the NPRs within cells by confocal microscopy. $\zeta$-potential measurements and the different electrophoretical mobility among the differently-modified NPRs confirmed successful NPR modifications. Additionally, fluorescence spectroscopy measurements confirmed that NPRs were susscessfully modified with TAMRA (see Additional file 1 : Figure S2-S3). Finally, the colloidal stability of the NPRs was evaluated incubating a suspension of NPRs in Dulbecco's modified Eagle's medium (DMEM) supplemented with $10 \%$ fetal bovine serum (FBS), $1 \%$ Lglutamine, and $1 \%$ penicillin/streptomycin during $24 \mathrm{~h}$ at room temperature. Then, the UV-vis spectra of the NPRs was measured and compared with the spectra before incubation in cell media. This test proved that the NPRs retain their colloidal stability in the conditions used for the cell studies with no sign of aggregation (see Additional file 1: Figure S4). Four NPR models were incubated with the cells: PEGylated NPRs (NPR-P), PEGylated NPRs modified with rhodamine only (NPR-PT), glucose (NPR-PG), and both molecules (NPR-PTG).

\section{Internalization of NPRs by cells}

We chose six common cell lines, i.e. three from human (A549: adenocarcinoma alveolar basal epithelial cells; MiaPaca: pancreatic carcinoma cells; and HeLa: cervical cancer cells) and three from mouse (MEF-SV40: embryonic fibroblasts immortalized with the virus SV40; B16: melanoma cells; and MC57G: fibrosarcoma cells). Several key factors brought us to select these cells from other common cell models. In the first instance, since we plan to test the effect of NPRs in a mouse model in vivo, the use of mouse cells in vitro is very useful to help to understand the upcoming in vivo results. Further, results in the mouse model require validation in a human system, the end potential target of this technology. In addition, since the grand aim of this research is to use NPRs as photothermal probes for cancer treatment and tumoral cell lines were chosen as the primary targets. Also, MEF-sv40 cells were chosen as a model of fibroblast non-tumoral cells since although they are immortalised, they are not tumorigeneic and thus they are usually used as a model of primary-like fibroblast cells. Lastly, as genuine primary cells, we used some of the main cell types interacting with and potentially responding against NPs after in vivo parental administration, peripheral blood mononuclear cells (PBMCs) and macrophages, the cells involved in the clearance of exogenous materials.

First, the uptake of the different types of NPs was analysed in the target cells in order to ensure that NPs interact and are internalized by those cell types. Accordingly,
NPRs were added to the cells at gold concentrations ranging from 25 to $200 \mu \mathrm{g} / \mathrm{mL}$, commensurate with values typically used in similar studies [22]. The change in sidescattered light (SSC) was analysed by flow cytometry, which is proportional to cell morphology (granularity and intracellular complexity). As shown in Additional file 1: Figure S5 there was an increase in the SSC of the cells incubated with all types of NPRs, and this change was particularly pronounced in the case of NPRs containing glucose indicating that cells changed their intracellular morphology after interaction with NPRs, a change that could be related to NPR uptake. The results of fluorescence confocal microscopy shown in Fig. 1 at two representative concentrations (100 and $200 \mu \mathrm{g} / \mathrm{mL}$ ), confirm that NPRs were readily internalized and accumulated inside the cells. As expected, the level of internalization varied from one cell type to another, likely due to the intrinsic endocytic properties of each cell type. Independently of the differences in the NPRs uptake between various cell types, the influence of surface coating on the internalization can be clearly observed in Fig. 1. NPR-PT probes were only poorly internalized by almost all of the cells lines, whereas coating with glucose (NPR-PTG probes) highly increased the level of internalization in all cell lines, even when the concentration of NPR-PT was doubled $(200 \mu \mathrm{g} / \mathrm{mL})$ in comparison with NPR-PTG. NPR-PT probes are labelled with the dye, but in terms of surface coating they are covered by a densely packed PEG coating, which, as shown in Fig. 1, prevents cell uptake, in agreement with previous results $[20,30]$.

\section{ROS generation by cells upon interaction with NPs}

ROS generation was investigated in all of the cell lines after $48 \mathrm{~h}$ of incubation, using increasing concentrations of two NPR probes (dye labelled probes were excluded because of fluorescence interference with the test). There are several fluorogenic probes commonly employed for selective detection of ROS such as $\mathrm{O}_{2}^{-}$, mitochondrial $\mathrm{O}_{2}^{-}$, $\mathrm{H}_{2} \mathrm{O}_{2}$ or $\mathrm{ONOO}^{-}$. However, the reliability and feasibility of these tests for detection and quantification of intracellular ROS have been questioned [31, 32]. In the context of ROS generation triggered by the interaction of NPRs with cells, they are however widely employed. Here, we used dihydroethidine (2HE) for "catching" intracellular $\mathrm{O}_{2}^{-}$, enabling for qualitative detection of the fluorescence product 2-hydroxyethidium $\left(2-\mathrm{OH}-\mathrm{E}^{+}\right)$. We decided to analyse the superoxide anion since this is the first and most abundant oxygen radical generated during the physiology and pathophysiology of ROS.

As shown in Fig. 2a, after $48 \mathrm{~h}$ of NPR incubation with the cells, the impact of NPR-PG in terms of ROS production is apparent in half of the cell lines (MEF, MC57G and HeLa cells). However, increasing concentrations of NPR-P 


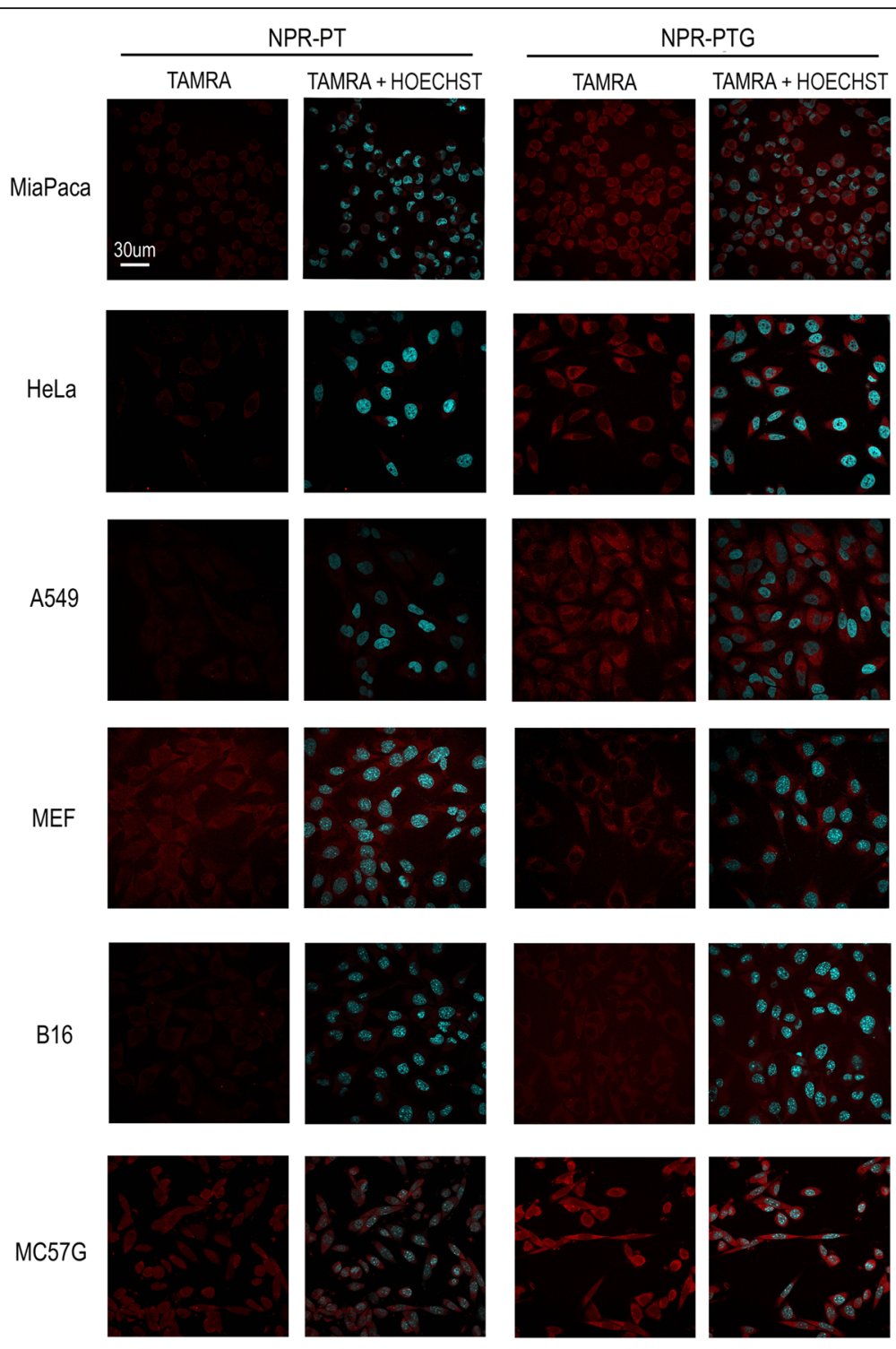

Fig. 1 Analysis of nanoparticles internalized within cells using confocal microscopy. The indicated cells were incubated with NPR-PT and NPR-PTG nanoparticles at four different concentrations $(25,50,100$ and $200 \mu \mathrm{g} / \mathrm{mL}$ ) for $24 \mathrm{~h}$ and were fixed with 4\% PFA and dyed with Hoechst 3342 (DNA), pictures were taken using a confocal microscope as indicated in experimental section. A representative experiment $200 \mu \mathrm{g} / \mathrm{mL}$ of NPR-PT and $100 \mu \mathrm{g} / \mathrm{mL}$ of NPR-PTG is shown. Scale bar: $30 \mu \mathrm{m}$

induce ROS generation only in MEF cells. The level of ROS generation also depends on the cell type. To be noticed, A549 cells, a highly resistant tumoral cell line widely used for in vitro toxicity studies, show the lowest ROS levels. However they presented a level of NPR internalization similar to the one observed in MEF and HeLa cells, which showed the highest ROS production. The cytotoxic drug staurosporine increases ROS in half of the cell lines although as in the case of NPRs at different levels, indicating that ROS production depends on the cell line. Again, these results provide crucial evidence on the importance of using several cell models to properly interpret the results employing NPs.

\section{Mitochondrial damage: Loss of mitochondrial membrane} potential

ROS generation is mostly a consequence of uncoupled electron mitochondrial transport and usually it is accompanied by a loss of mitochondrial membrane potential. In order to investigate the possible mitochondrial damage caused by NPRs, cells were supplemented with increasing concentrations of NPR-P or NPR-PG. Figure $2 \mathrm{~b}$ shows the important impact of increasing concentrations of NPRs on the mitochondrial membrane potential $\left(\Delta \Psi_{\mathrm{m}}\right)$. Although there are differences between the cell lines concerning the loss of $\Delta \Psi_{\mathrm{m}}$, the concentration and functionalization effect is apparent. However, it 

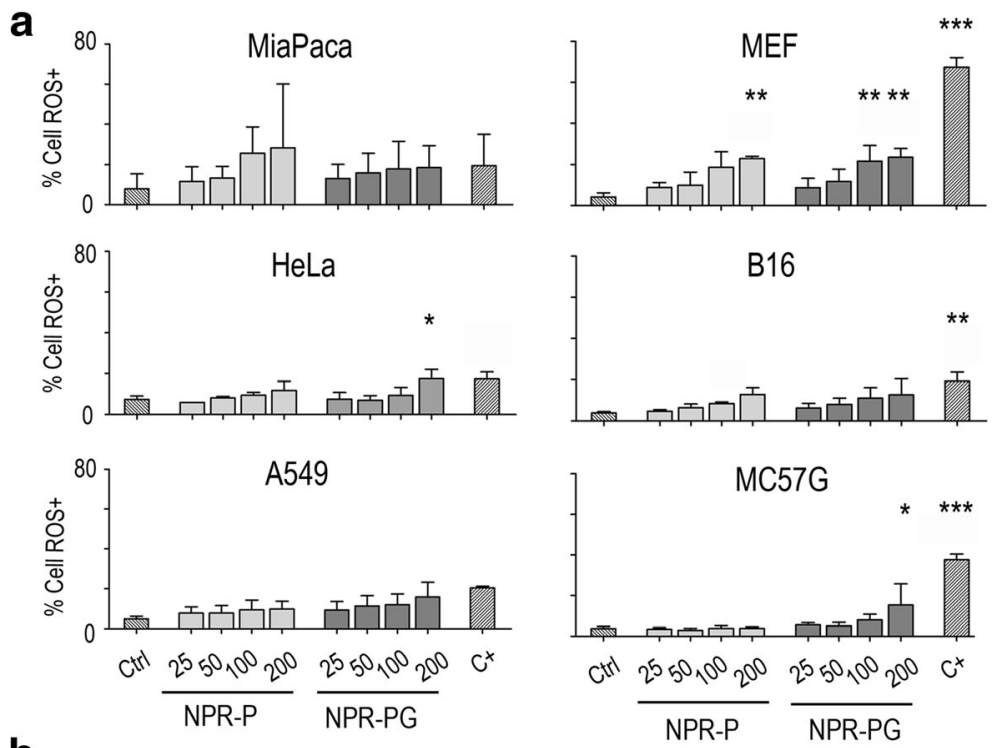

b
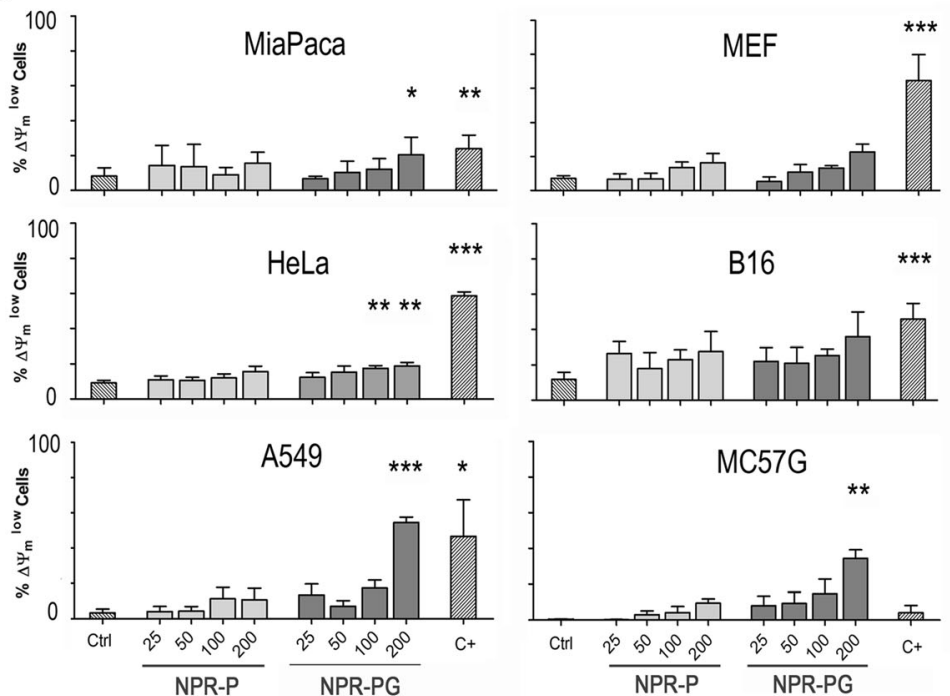

Fig. 2 Analysis of the effect of NPRs on ROS production and loss of mitochondrial membrane potential by flow cytometry. Analysis of the superoxide anion generation by flow cytometry. The indicated cells were mock treated (ctrl) or incubated with NPR-P and NPR-PG nanoparticles at four different concentrations $\left(25,50,100\right.$ and $200 \mu \mathrm{g} / \mathrm{mL}$ ) for $48 \mathrm{~h}$. (a) Superoxide generation was monitored using $2 \mathrm{HE}$ and (b) $\Delta \Psi_{\mathrm{m}}$ was monitored using $\mathrm{DIOC}_{6}$ as indicated in experimental section. As positive control $(\mathrm{C}+$ ) staurosporine $1 \mu \mathrm{M}$ was used. Data represent mean values \pm SD from three independent experiments ${ }^{*} p<0.05,{ }^{* *} p<0.01,{ }^{* * *} p<0.001$

should be stressed that, when ROS and $\Delta \Psi_{\mathrm{m}}$ data are directly compared for each cell line, there are clear differences between them. For example, loss of $\Delta \Psi_{\mathrm{m}}$ correlates with ROS generation in HeLa, MEF, MC57G and B16 cells; yet the impact of NPR internalization on ROS generation and loss of $\Delta \Psi_{\mathrm{m}}$ is more evident in HeLa and MC57G cells than in B16 cells. In contrast, loss of $\Delta \Psi_{\mathrm{m}}$ does not correlate with ROS generation in A549 cells. Therefore, although the generation of ROS and loss of $\Delta \Psi_{\mathrm{m}}$ correlate with NPR concentration (in particular for glucose-modified NPRs), different cell lines respond differently. TAMRA seemed to have an effect on the loss of
$\Delta \Psi_{\mathrm{m}}$ and thus the impact of glucose was difficult to assess in TAMRA functionalized NPR (data not shown). Again staurosporine induced loss of $\Delta \Psi_{\mathrm{m}}$ in all cases except for MC57G cells.

\section{Apoptosis and NPRs}

To analyse apoptosis we monitored phosphatydylserine (PS) translocation and membrane damage by flow cytometry using annexin-V and 7-AAD double staining, which allowed us to distinguish between early apoptotic cells (annexinV+/7AAD- cells) and late apoptotic/necrotic cells (annexinV+/7AAD+ cells). As shown in Fig. 3, 

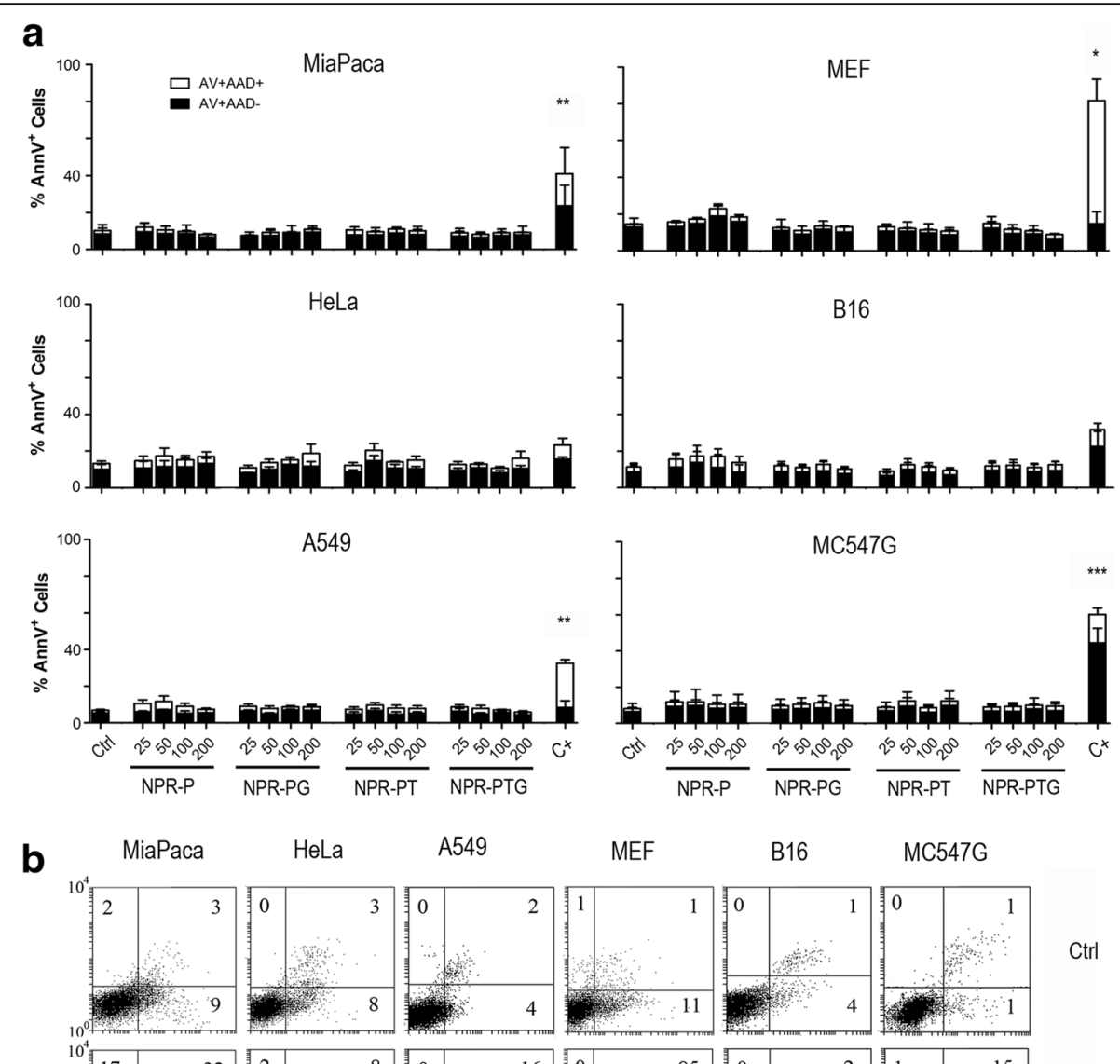

Ctrl
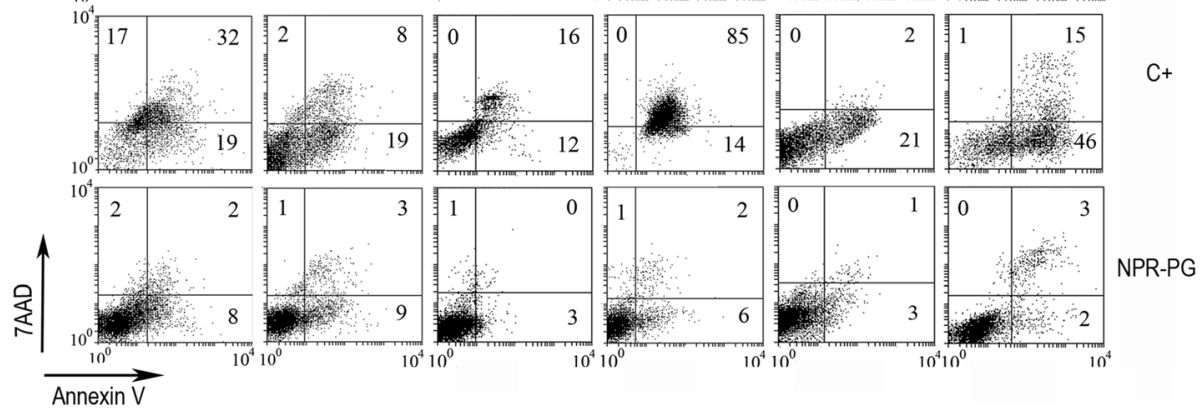

Fig. 3 Analysis of phosphatidilserine (PS) translocation and membrane permeabilisation by flow cytometry. The indicated cells were mock treated (ctrl) or incubated with four types of nanoparticles (NPR-P, NPR-PG, NPR-PT, NPR-PTG) at four different concentrations (25, 50, $100 \mathrm{and} 200 \mathrm{\mu g} / \mathrm{mL}$ ) for $48 \mathrm{~h}$ and PS translocation and membrane permeabilisation were monitored using annexin- $V$ and 7AAD respectively as indicated in experimental section. As positive control $(C+)$ staurosporin $1 \mu \mathrm{M}$ was used. (a) Data represent mean values $\pm \mathrm{SD}$ from three independent experiments. ${ }^{*} p<0.05$, ${ }^{* *} p<0.01$, ${ }^{* * *} p<0.001$. (b). A representative experiment is shown at the concentration of $100 \mu \mathrm{g} / \mathrm{mL}$. Numbers correspond to the percentage of cells in each quadrant

neither apoptosis nor necrosis was observed in any cell type for any of the NPR derivatives. Staurosporine induced PS translocation in most of the cell lines although at different extent. Although Annexin-V staining did not reach statistically significant difference in $\mathrm{HeLa}$ and B16 cells, a clear annexin-V positive cell population could be detected in the dot plots (Fig. 3b) in both cell lines indicating delayed cell death in these cell lines (see Fig. 4).
Cell proliferation: Clonogenic studies

Finally, to certainly confirm that NPRs did not affect cell viability in vitro, we analysed the effect of NPRs on the ability of the different cell lines to grow and form colonies 10 days after incubation, an assay that is considered as the gold standard to assess cell viability. As shown in Fig. 4, MEF, MiaPaca, HeLa, B16 and A549 cells incubated with the highest concentration of the four NPRs probes form the same number of colonies as 

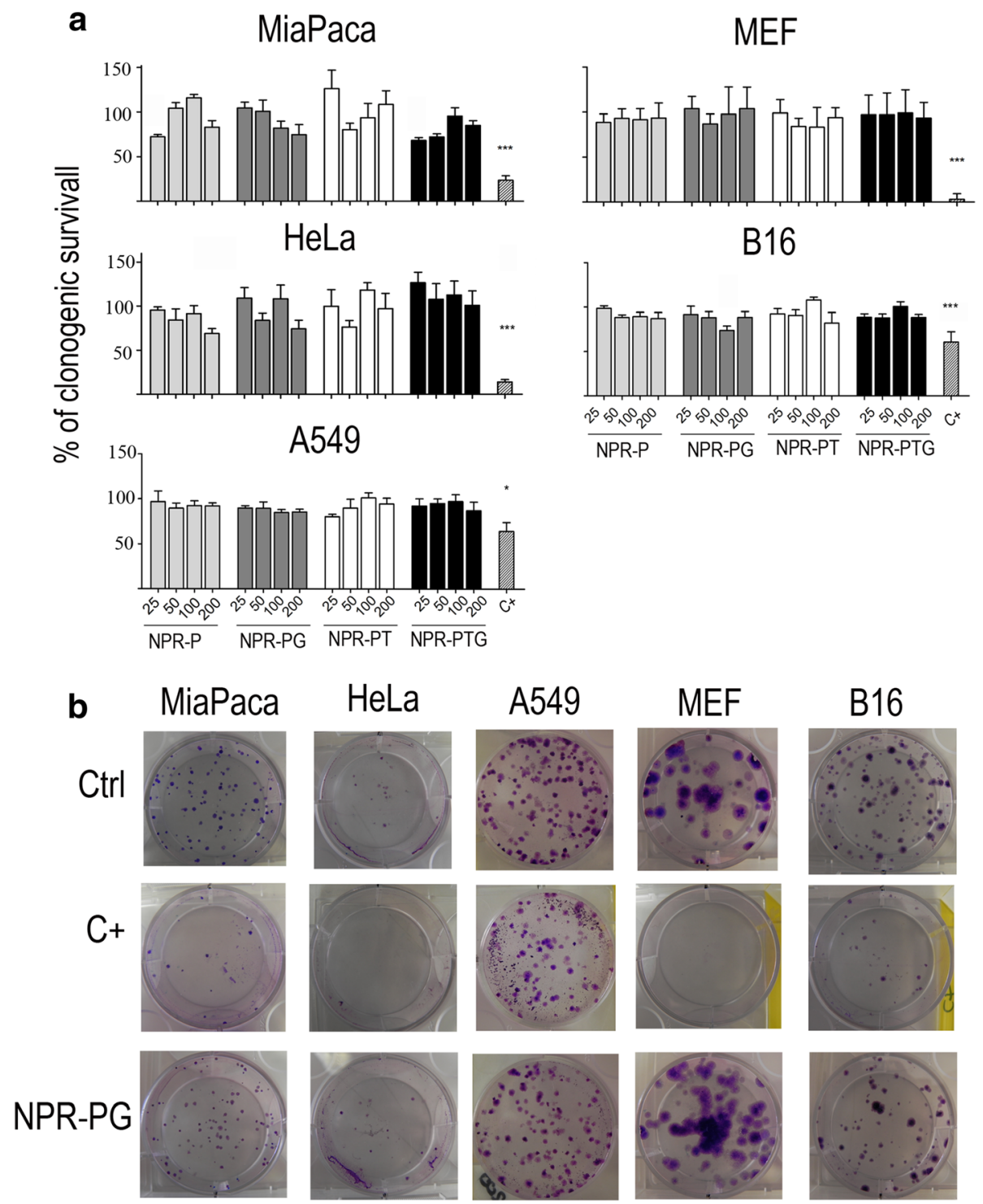

Fig. 4 Analysis of the effect of NPRs on cell survival using a clonogenic assay. The indicated cells were mock treated (ctrl) or incubated with four types of nanoparticles (NPR-P, NPR-PG, NPR-PT, NPR-PTG) at four different concentrations (25, 50, $100 \mathrm{and} 200 \mu \mathrm{g} / \mathrm{mL}$ ) for $48 \mathrm{~h}$. Subsequently, 100 cells were seeded per well by triplicates and incubated in fresh medium for 10 days. After that, cells were stained with Crystal Violet and colonies were counted as described in experimental section. As positive control $(\mathrm{C}+$ ) staurosporine $1 \mu \mathrm{M}$ was used. (a) Survival was calculated as percentage of colonies growing referred to the number of colonies in the negative control. Data represent mean values \pm SD from three independent experiments. ${ }^{*} p<0.05,{ }^{* *} p<0.01,{ }^{* * *} p<0.001$. (b) Pictures from single wells of a representative experiment $(100 \mu \mathrm{g} / \mathrm{mL})$ are shown

the controls. Consequently cell growth and capability of forming colonies (cell viability) are two crucial factors that are not influenced by the incubation of cells with any of the four NPR probes. In contrast, cells incubated with staurosporine showed low proliferation rates in all cell lines, despite the different sensitivity in terms of ROS production and loss of $\Delta \Psi_{\mathrm{m}}$ observed between them. These results prove that staurosporine is able to induce cell death in all cell lines, but with a delayed kinetics in B16 and HeLa cells (compare with Fig. 3a).
This test cannot be applied to all cell lines (MC57G) because of the intrinsic ability of specific cells to form colonies; however, this finding undoubtedly confirms that ROS and mitochondrial changes after NPR exposure are not toxic for the tested cells, including human and mouse cells of tumoral (HeLa, MiaPaca, A549, B16) and non-tumoral (MEF) origin.

\section{Primary cells: Macrophages and PBMCs}

The experiments performed above indicate that gold NPRs are neither cytotoxic nor cytostatic for transformed 
cells. However this does not necessarily mean that they would not present toxicity in the context of a physiological setting where they encounter with "healthy" cells. To this goal the uptake in primary cells was assayed using the same protocols as in the immortalized cell lines. We chose cells from the immune system (blood lymphocytes and differentiated macrophages) since they are the first ones encountered by NPs when administered in vivo. In the case of bone marrow derived macrophages that presented a inflammatory M1 phenotype (see methods), confocal microscopy confirmed internalization of both NPR-PT and NPR-PTG probes (Fig. 5a). Analysis of ROS generation and loss of $\Delta \Psi_{\mathrm{m}}$ suggested that both processes were induced by all types of NPRs (data not shown). Unfortunately a detailed and reliable quantification of those processes was not possible due to the high level of intrinsic autofluorescence of the macrophages, which is quenched by NPRs. Despite this technical problem, determination of PS translocation (annexin V) and membrane permeabilisation (7AAD) (Fig. 5b) indicated that NPRs are not toxic to the macrophages. Although staurosporine was not able to kill the macrophages as analysed by the annexin V staining, this was not due to an inherent inability to translocate PS since other stimuli like cytotoxic $\mathrm{T}$ cells or bacterial infection induced PS translocation in this cell type correlating with loss of cell viability (data not shown and [33]).

In contrast to macrophages and immortalised cell lines, confocal microscopy pictures show that the NPRPT and NPR-PTG probes displayed a poor internalization by human blood lymphocytes (PBMCs) (Fig. 5c). $\Delta \Psi_{\mathrm{m}}$ and ROS generation were less affected than in cell lines, likely due to the lower internalization rate observed here (Fig. 5d and e) and, again, PS translocation and membrane permeabilisation were absent (Fig. 5f), indicating that NPRs were neither toxic for lymphocytes.

\section{In vivo toxicity studies}

Intravenous administration of $6 \mu \mathrm{g} / \mathrm{g}$ NPR-PTG did not affect animal body weight $72 \mathrm{~h}$ or 4 months after administration (Fig. 6a and c). Neither other signs of toxicity or animal distress such as disheveled hair, irregular respiration, gastrointestinal symptoms, immobility or death were observed. After extracting the main organs, differences in organ index were not detected, except for kidneys $72 \mathrm{~h}$ after the NPs injection, which appeared bigger when compared to those of control mice (Fig. 6b). There were no observable differences in organ indexes four months after injection (Fig. 6d). Among four blood biochemical parameters of systemic or specific organ damage (ALT -liver-, CK -muscle-, creatinine -kidney- and LDH -any tissue/cell-) and two main inflammatory cytokines (IFN $\gamma$ and TNF $\alpha$ as markers of innate and adaptative inflammatory responses) that were analyzed no significant variations were found, indicating that NPRs did not induce any detectable tissue or cell damage, including inflammatory response (Fig. 7).

Next we analysed tissue sections by haematoxylin/ eosin (HE) staining to search for structural changes or apparent histopathological abnormalities. After $72 \mathrm{~h}$ no significant changes were found, in any of the analyzed tissues including liver, spleen, kidney, heart, lung, thymus and reproductive organs. In turn, four months later, hepatocytes were enlarged and displayed a high number of vacuoles in their cytoplasm (Fig. 8). These changes appeared more frequently in the central lobular section, being compatible with a hydropic change or vacuolar degeneration. The presence of glucogen deposits was discarded as analysed employing a glucogen specific dye (Additional file 1: Figure S6). Also, the presence of Kupffer cells with an enlarged cytoplasm was observed. These cells contained a black pigment that could be compatible with the presence of NPR-PTG (Fig. 8c). Although the white pulp of the spleen was hypertrofic, the architecture of the organ was not altered in a considerable way (Fig. 9b). Macrophages with a black pigment in the cytoplasm (compatible with the NPR-PTG) were identified in the white pulp (Fig. 9c and d).

\section{Biodistribution of the NPRs in vivo}

Fluorescence microscope studies were carried out to determine if the NPRs bearing a fluorophore were present in the tissue sections of the main organs, i.e. liver, spleen, kidneys, heart, lungs, thymus and reproductive organs. $72 \mathrm{~h}$ after the intravenous injection it was not possible to find in any trace of a fluorescence signal in these organs; but it was identified in the urine collected $24 \mathrm{~h}$ after injection. Importantly however, the ICP-MS analysis did not detect gold in urine (data not shown) thereby suggesting that the fluorophore was detached from NPRs, which is in accordance with previous work [34]. Thus, to corroborate the biodistribution of the NPRs, ICP-MS of the organs was carried out. $72 \mathrm{~h}$ after treatment NPRs were found in the spleen and liver, approximately $0.4 \mu \mathrm{g} \mathrm{Au}$ per mg of lyophilized organ. The amount of NPRs found in the liver corresponded to $25 \%$ of the total amount of NPRs originally injected; whereas the spleen contained just $5 \%$. No NPRs were detected in other organs or in the urine (Fig. 10). Note that the organs that were collected are the ones that more frequently accumulate NPs (spleen, liver, lungs) and other organs essential for other vital functions, such as the reproductive organs and thymus were also collected. The remaining NPRs might therefore be contained in other areas not collected, such as the intestines and canvas or be excreted in the faeces.

Four months after the injection, NPR-PTG were still present in liver and spleen. While in the liver the NPs 


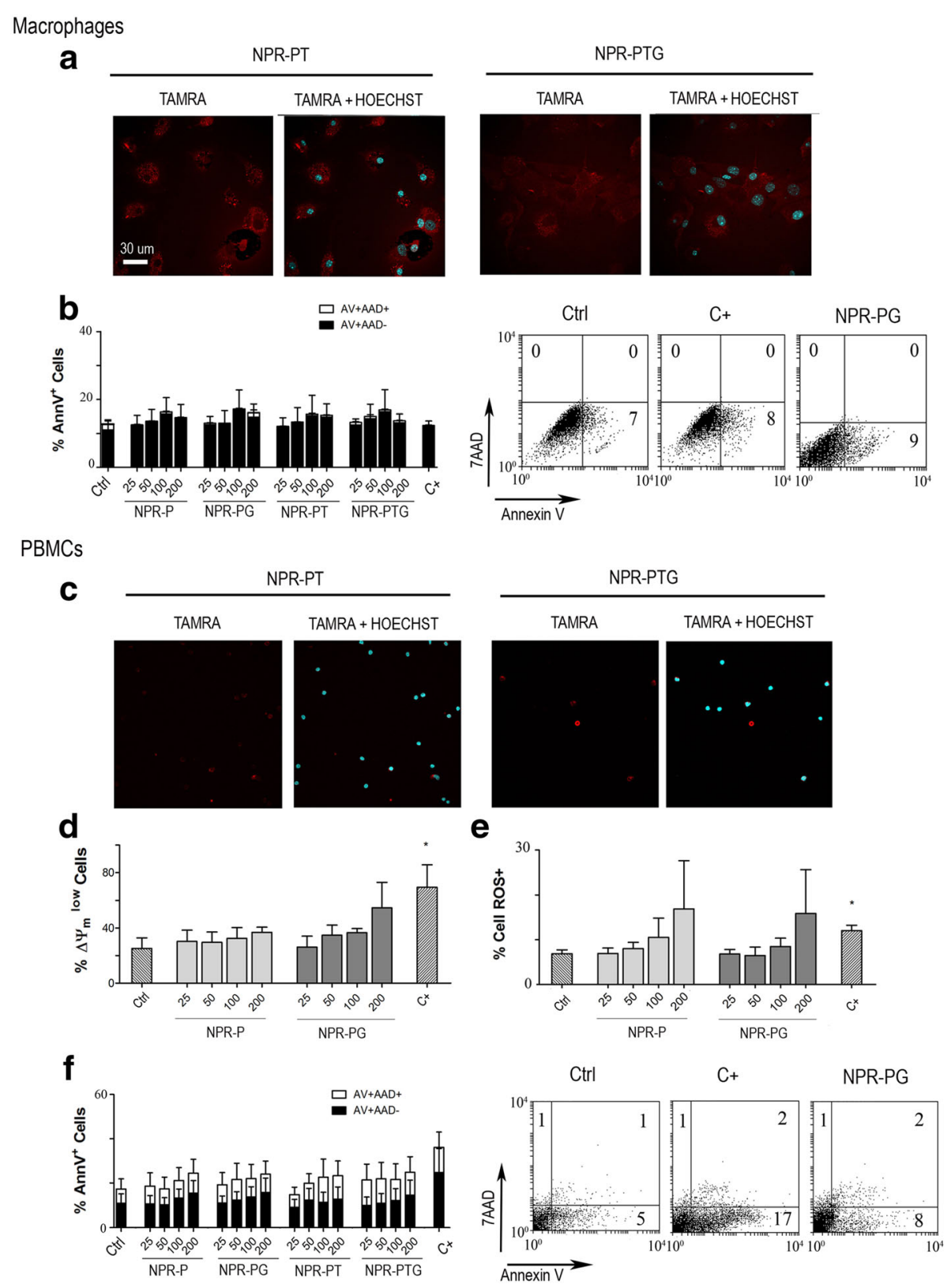

Fig. 5 Analysis of the effect of nanoparticles on the viability of mouse primary macrophages and human PBMCs. Mouse bone marrow derived macrophages and human PBMCs were mock treated (ctrl) or incubated with four types of nanoparticles (NPR-P, NPR-PG, NPR-PT, NPR-PTG) at four concentrations (25, 50, 100 and $200 \mu \mathrm{g} / \mathrm{mL}$ ) for $24 \mathrm{~h}$ as indicated in experimental section. (a) Analysis of nanoparticles entry in macrophages using confocal microscopy. A representative experiment $100 \mu \mathrm{g} / \mathrm{mL}$ of NPR-PTG and $200 \mu \mathrm{g} / \mathrm{mL}$ of NPR-PT is shown. (b) Detection of phosphatydylserine translocation (AnnexinV) and cell membrane permeabilisation (7AAD) in macrophages by flow citometry. (c). Analysis of nanoparticles entry in PBMCs using confocal microscopy. A representative experiment $100 \mu \mathrm{g} / \mathrm{mL}$ of NPR-PTG and $200 \mu \mathrm{g} / \mathrm{mL}$ of NPR-PT is shown. (d). Analysis of $\Delta \Psi_{\mathrm{m}}$ loss (DIOC 6 ), (e) detection of superoxide anion generation and ( $\mathbf{f}$ ) detection of phosphatydylserine translocation (AnnexinV) and cell membrane permeabilisation (7AAD) in PBMCs by flow citometry. Data represent mean values \pm SD from three independent experiments. ${ }^{*} p<0.05,{ }^{* *} p<0.01$, ${ }^{* * *} p<0.001$. As positive control $(\mathrm{C}+$ ) staurosporine $1 \mu \mathrm{M}$ for macrophages and cladribine $5 \mu \mathrm{M}$ for PBMCs was used. Scale bar: $30 \mu \mathrm{m}$

amount was reduced to $10-15 \%$ of the injected dose, in the spleen this amount remained similar to that of $72 \mathrm{~h}$ post injection (3-5\%) suggesting that the liver was somehow able to degrade at least in part the NPR-PTG.
To confirm the presence of the NPR-PTG in the spleen and liver four months after injection, TEM and STEM along with EDX were performed (Fig. 11). As expected, NPR-PTG were found in macrophages, however, the shape of the NPR-PTG in the liver was different 

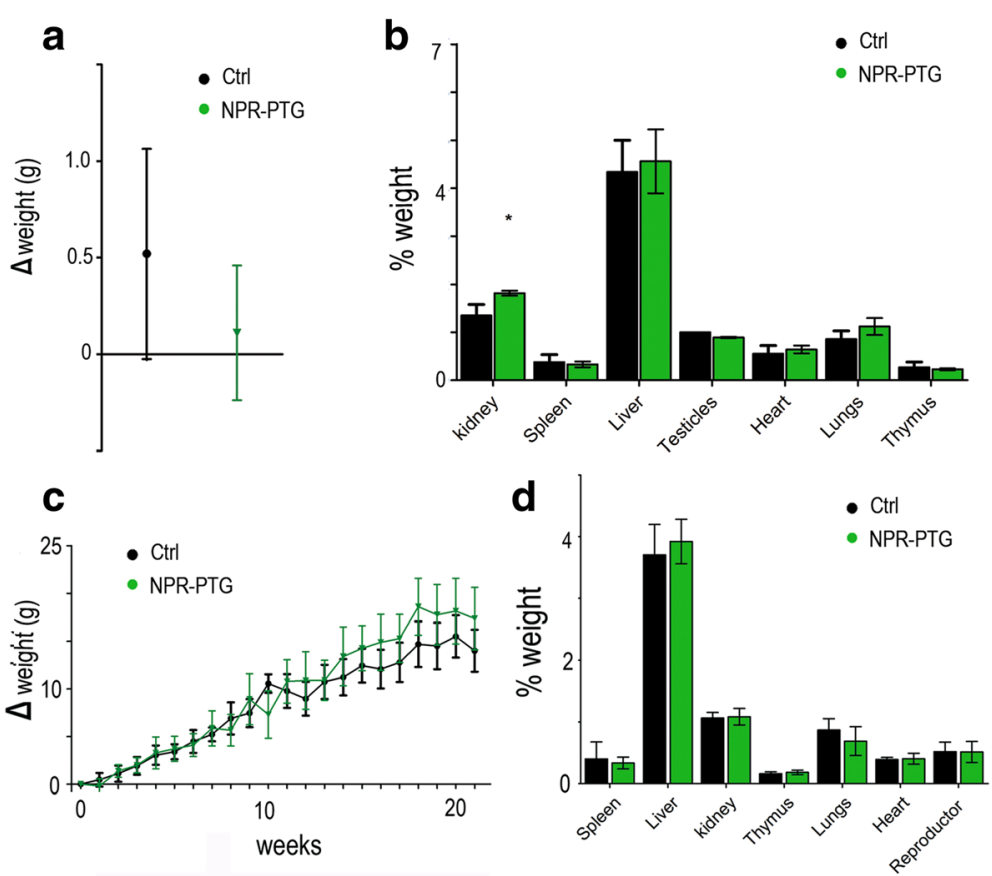

Fig. $\mathbf{6}$ Analysis of (a and $\mathbf{c}$ ) the weight gain of mice treated with nanoparticles and (b and $\mathbf{d}$ ) the relative weight of the organs after treatment. Data of (a and $\mathbf{b}$ ) 3 days and (c and $\mathbf{d}$ ) 4 months after treatment. Mice were injected (i.v) with $6 \mu \mathrm{g} / \mathrm{g}$ NPR-PTG (green) or the same volume of PBS in the group control (black). The mice weight was measured (a) before and after 3 days of the treatment and (c) weekly during the following 4 months. (b) and (d) the mice were sacrificed and the weight of the different organs were measured after treatment and referred to the mice weight. Data represent mean values \pm SD from 5 mice. ${ }^{*} p<0.05$

from that of the original NPR, which can be related to a digestion process.

\section{Discussion}

Toxicity is a major concern that needs to be carefully addressed before a new nanomaterial can be considered to be translated into in vivo biomedical clinical application. Moreover, it should be tested at different levels including cell uptake and pharmacokinetics [35], immune/ inflammatory responses [36], genotoxic effects or cell death. The overall aim of this work was to investigate the toxicity of anisotropic gold nanoprisms (NPRs) and the influence of the surface coating, focusing on a detailed analyses of its impact on oxidative stress and cell death in vitro as well as toxicity and biodistribution in vivo. To this aim we have employed in vitro cell models and validated the results in vivo in mice. We used sulphate-capped NPRs with ca. $150 \mathrm{~nm}$ in length and $10 \mathrm{~nm}$ thicknesses (see Additional file 1: Figure S1) modified with PEG. PEG molecules are considered to be among the most efficient antifouling agents used for stabilizing NPs for bioapplications; especially the high molecular weight derivatives such as the $5 \mathrm{kDa}$ chain used in this study [37]. Confirming it, all tests performed on the final modified NPRs proved that the NPRs retain their colloidal stability in the conditions used for the cell studies (see Additional file 1: Figure S4).
We show that cellular internalization of NPRs varies for different cell lines, which may be explained by the various different intrinsic phagocytic properties and/or levels of glucose requirement. Upon confirming the internalization of NPRs by all cell lines, the possible toxic effects induced on those cell types were examined. The pioneering work of $\mathrm{Nel}$ and co-workers has established ROS generation as among one of the most common effects caused by internalized NPs [17], although it remains unclear precisely which properties of NPs contribute to the ROS induction. Several studies have focused on surface characteristics, size, shape and other parameters related to increased cytotoxicity by ROS production [20, 38, 39]. A recent study performed on differently functionalized gold and silver NPs highlights also the importance of the components of cell culture medium like serum protein, which upon adsorbtion onto the NPs surface (so-called protein corona) may change the surface charge of NPs and therefore affect their ability to produce ROS [40].

Our results regarding ROS generation indicate that the association of cells with NPRs induced ROS generation in half of the cell lines tested, which was accompanied by loss of $\Delta \Psi_{\mathrm{m}}$ in some cases. Intracellular ROS accumulation can trigger diverse modalities of cell death including apoptosis and necrosis [41]. In line with our findings Soenen et al. found ROS generation and loss of $\Delta \Psi_{\mathrm{m}}$ in 


\section{Creatinine}

\section{LDH}
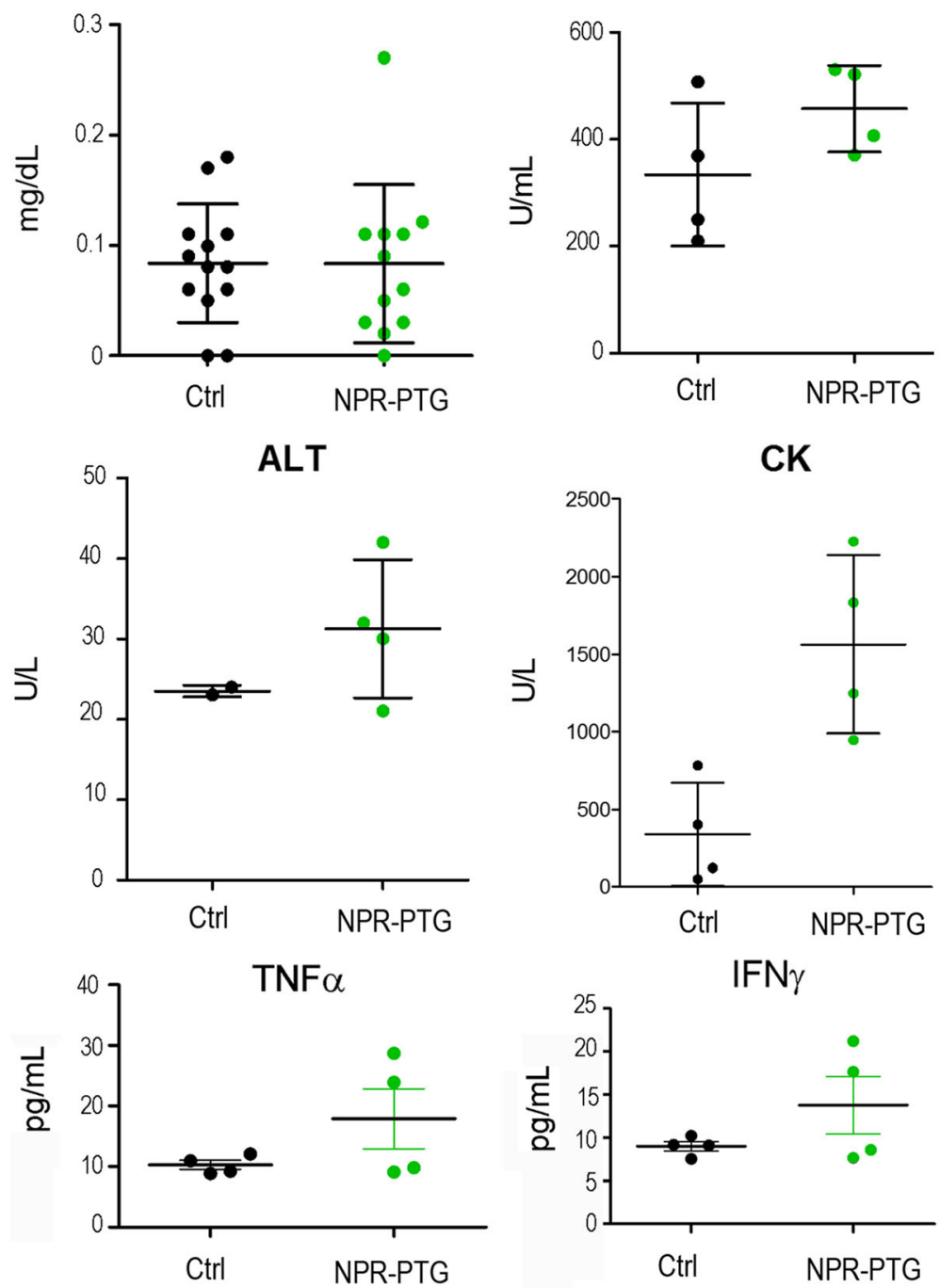

Fig. 7 Analysis of four blood biochemical parameters of systemic or specific organ damage (ALT -liver-, CK -muscle-, creatinine -kidney- and LDH -any tissue/cell-) and two main inflammatory cytokines (TNFa and IFNY). Mice were injected (i.v) with $6 \mu \mathrm{g} / \mathrm{g}$ NPR-PTG (green) or the same volume of PBS (black) in the group control. The mice were sacrificed after four months and the blood was collected by cardiac punction as indicated in experimental section. Dots represent values from each mouse and bars \pm SD

a multiparametric study with polymer coated gold NPs of $4 \mathrm{~nm}$ in diameter and at concentrations above $100 \mathrm{nM}$ (concentration of gold ca. $40 \mu \mathrm{g} / \mathrm{mL}$ ) [22]. However in this case, internalization of those NPs caused DNA damage and cell cytotoxicity. Loss of $\Delta \Psi_{\mathrm{m}}$ and cytotoxicity were prevented by using a ROS scavenger. In contrast to these findings a recent work has highlighted the role of mitochondrial depolarization in tumoral cells, following uptake of positively charged gold NPs as a defense mechanism for counteracting the increased levels of cytosolic $\mathrm{Ca}^{2+}$ induced by NP uptake [42]. In line with these findings we show that ROS generation and mitochondrial perturbation are not sufficient to cause apoptosis even in primary cells. Remarkably,
NPRs do not induce apoptotic or necrotic features even in cells where the $\Delta \Psi_{\mathrm{m}}$ was down-regulated. In contrast, loss of $\Delta \Psi_{\mathrm{m}}$ and/or ROS generation induced by staurosporine (or other stimuli like cytotoxic $\mathrm{T}$ cells or bacterial infection in the case where staurosporine is not effective -data not shown-) were accompanied by induction of phosphatidylserine (PS) translocation and membrane permeabilisation and lower number of colony formation, indicating that lack of pro-apoptotic markers during incubation with NPRs was not due to a general defect in the cells used. Here, it should be noted there are different ways to down-regulate $\Delta \Psi_{\mathrm{m}}$ and not all of them lead to the loss of cell viability. One of them is the formation of a permeability transition pore (PTP) that involves 

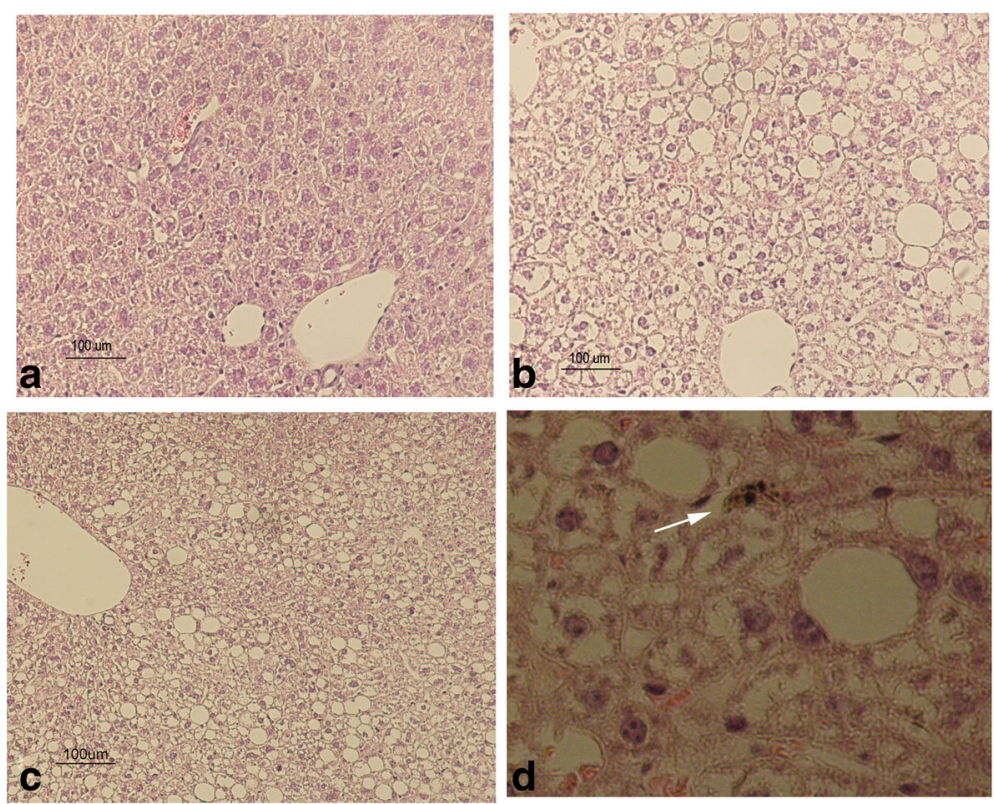

Fig. 8 Hematoxylin-Eosin stain of the liver of mice treated with NPRs. Mice were injected (i.v) with (b-d) $6 \mu \mathrm{g} / \mathrm{g}$ NPR-PTG or the same volume of PBS in the (a) group control. The mice were sacrificed after four months and organs were fixed and processed for the H\&E stain, as indicated in experimental section. Representative images are shown

both inner and outer mitochondrial membranes. Its formation is reversible and regulated by intracellular $\mathrm{Ca}^{2+}$ and ROS. If cells are able to reduce the levels of ROS and $\mathrm{Ca}^{2+}$, the pore is closed and the mitochondrion recovers its function. On the contrary, the permanent opening causes mitochondrial rupture by osmotic shock, triggering cell death [43]. This could help to explain apparent contradictory results observed in different studies. Thus, a reliable measure of toxicity based on ROS production and loss of $\Delta \Psi_{\mathrm{m}}$ will be dependent on the intensity of the stimulus and the ability of the cell to counteract the effect of NPs uptake. Supporting this
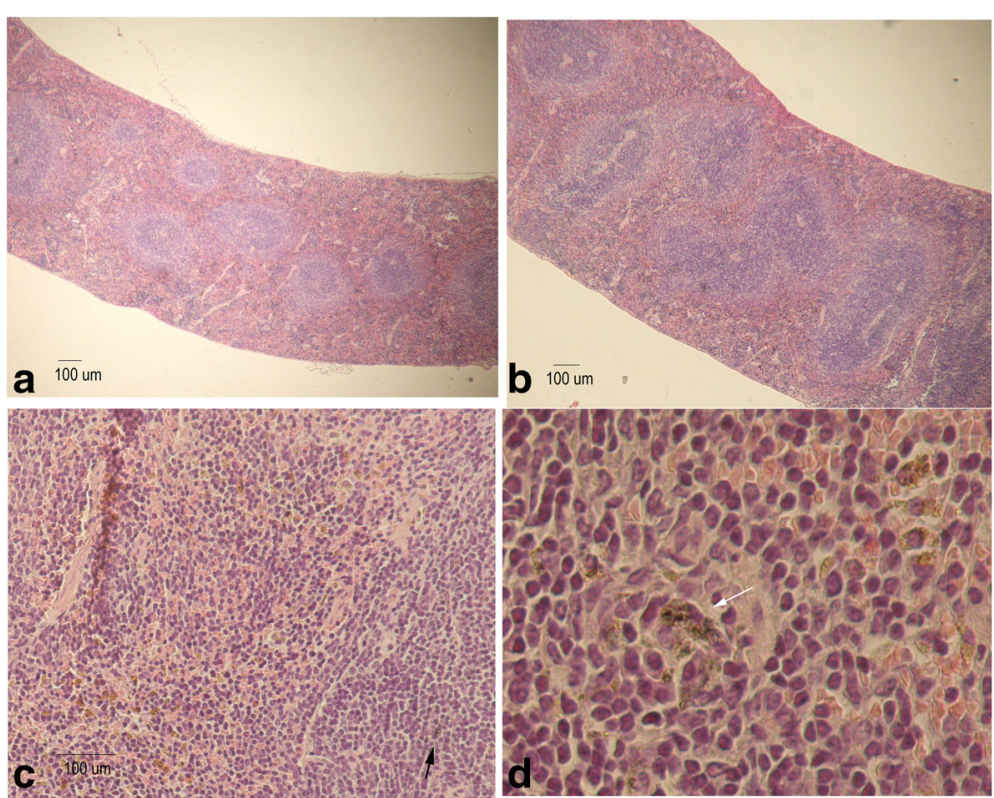

Fig. 9 Hematoxylin-Eosin stain of the spleen of mice treated with nanoparticles. Mice were injected (i.v) with (b-d) $6 \mu \mathrm{g} / \mathrm{g}$ NPR-PG or the same volume of PBS in the (a) group control. The mice were sacrificed after 4 months and the organs were fixed and processed for the H\&E stain, as indicated in experimental section. Representative images are shown 

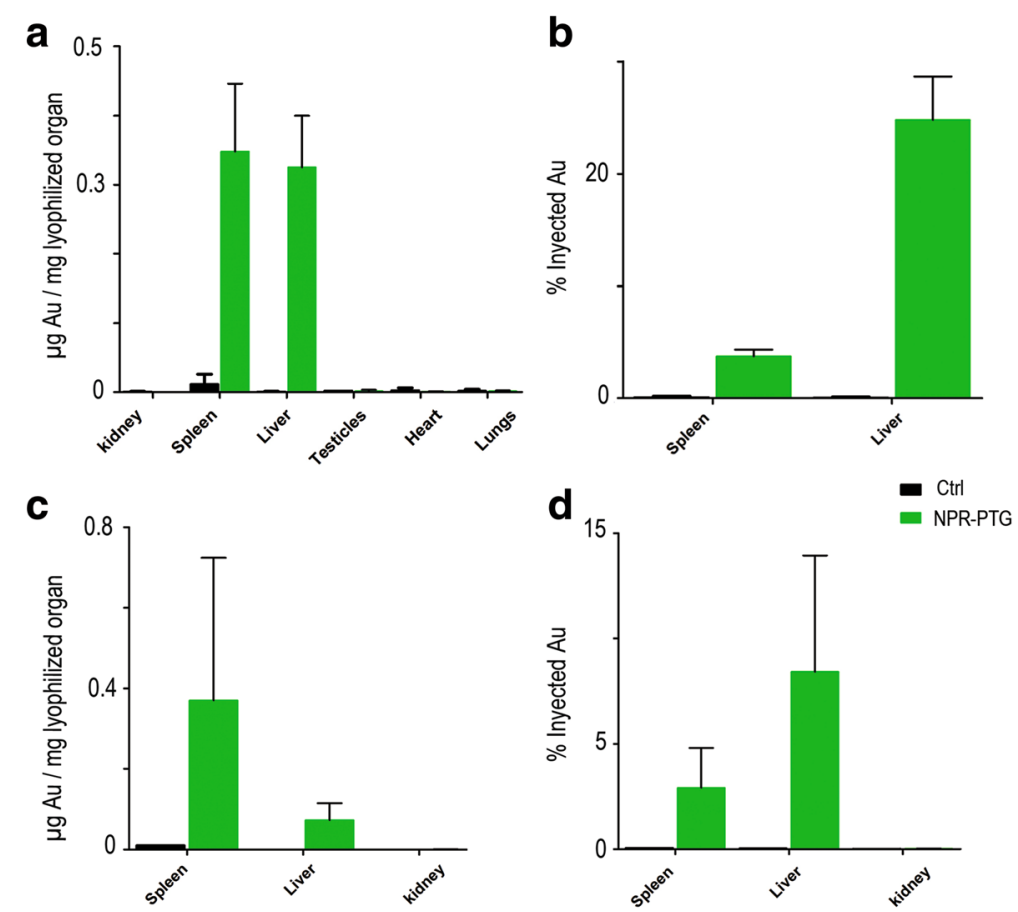

Fig. 10 Biodistribution of nanoparticles in vivo. Mice were injected (i.v) with $6 \mu \mathrm{g} / \mathrm{g}$ NPR-PG (green) or the same volume of PBS in the group control (black). The mice were sacrificed after ( $\mathbf{a}$ and $\mathbf{b}$ ) 3 days or (c and $\mathbf{d}$ ) four months and the organs were lyophilized and processed as indicated in experimental section, in order to analyse the quantity of gold by ICP-MS. Data represent mean values \pm SD from three mice

hypothesis, we have recently shown that the production of high levels of ROS and mitochondrial depolarisation during photothermal therapy using gold NPRs irreversibly lead to cell death [8].

Our data clearly indicate that internalization of NPRs induces signs of cell damage like ROS generation and mitochondrial depolarisation in some cell lines; yet those effects are not sufficient to compromise cell viability as confirmed using clonogeneic assay, the gold standard for analysing cell toxicity. In contrast to the widely used MTT test that only indicates the proliferation status of the cells, a clonogeneic assay tests the ability of single cells to form colonies 10 days after exposure to a specific stimulus [44]. In our case, these assays indicated that NPRs do not affect cell viability at any level including DNA damage or cell cycle arrest. Additionally, this finding indicates that to really assess cellular toxicity of NPs employing in vitro models, several cell types of different origin should be tested using a combination of different assays.

All these results employing transformed cells were confirmed on primary "healthy" cells, such PBMCs and macrophages. NPRs were internalized by macrophages; however, due to the phagocytosis capacities of macrophages no differences were observed in the internalization of different types of NPRs. Mirroring the results obtained with immortalized cell lines, the viability of the macrophages was not compromised. In contrast to macrophages and immortalised cell lines, NPRs were poorly internalized by human PBMCs and thus, ROS generation and $\Delta \Psi_{\mathrm{m}}$ lost were less evident than in the case of the tumour cell lines. Again, NPRs were neither toxic for lymphocytes.

Finally, the absence of toxicity in cell models was confirmed in vivo, by treating mice with NPR-PTG and testing the main serum biomarkers of tissue damage and inflammation as well as NP accumulation in organs by anatomy pathology. Although we found that NPRs were accumulated in liver and spleen four months after injection, the animals did not show any sign of mortality or morbidity and all serum and tissue toxicity markers remained unaltered, including those reporting a inflammatory immune response. These results indicate that either in contrast to cell models mitochondrial perturbations are not happening in vivo or if mitochondrial function is also affected in vivo, it is not sufficient to cause acute or chronic toxicity at least during the time frame analysed (four months). Several works have analysed in vivo toxicity of gold nanoparticles with different sizes and forms employing different administration ways [45-48]. A direct comparison with our findings is difficult since administration route, size and morphology (rod, sphere, etc) dramatically change in vivo NP behavior and most of the works have employed gold nanospheres. In these studies it was shown that i.v. 


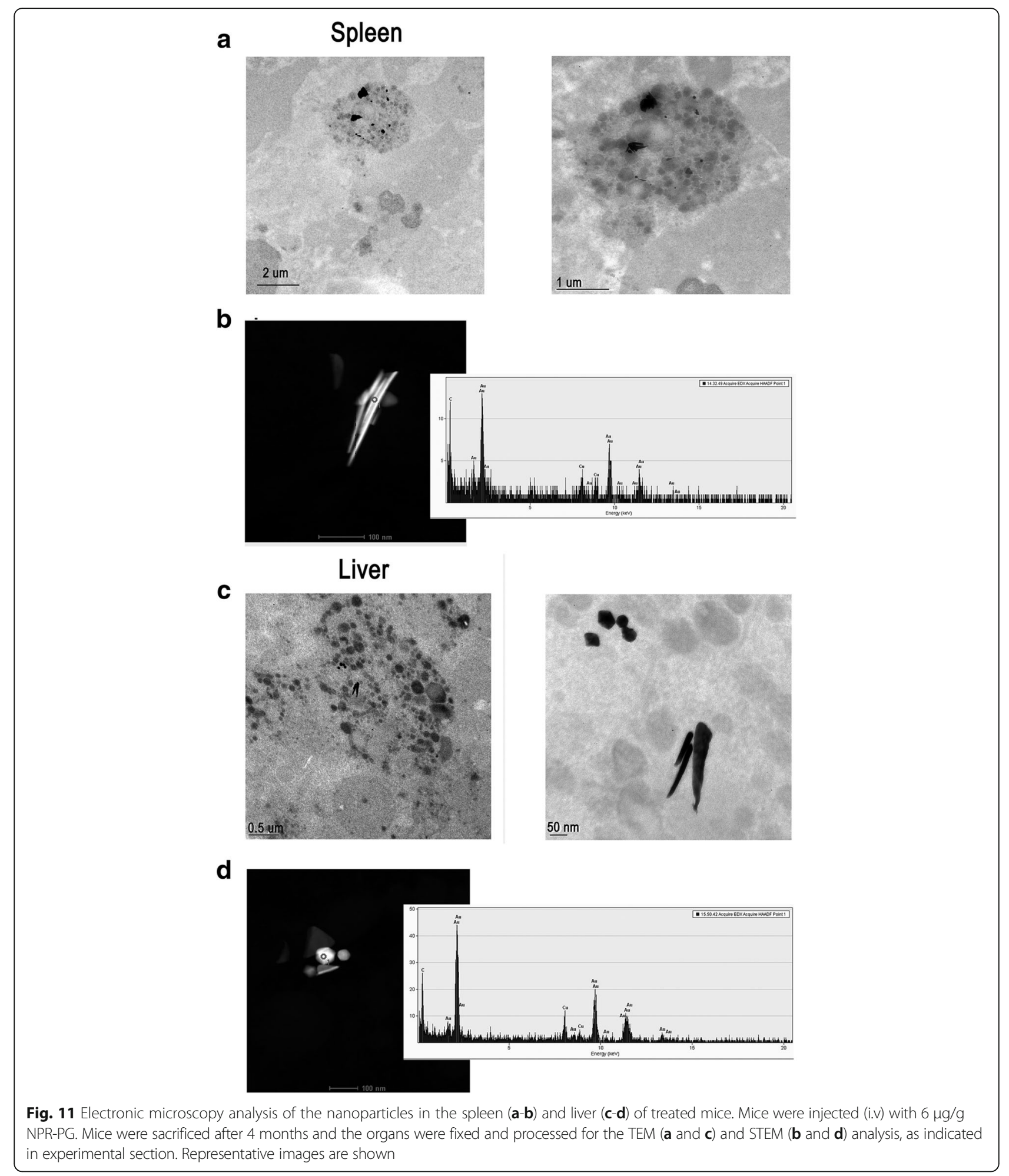

administration lead to a liver and spleen accumulation as found here employing NPRs, while oral administration lead to kidney accumulation. Subsequently and in line with our results it was shown that while oral or i.p. administration of gold nanospheres induced toxic effects in mice, i.v. injection did not [47]. In a recent study, $24 \mathrm{~h}$ after the injection of $2.7 \mathrm{mg} / \mathrm{kg}$ PEGylated NPRs $(61.51 \pm 2.91 \mathrm{~nm})(57 \mu \mathrm{g}$ per mouse $)$ it was found that the nanoparticles presented the highest level of accumulation in the spleen, whereas the liver and intestine had 
the next highest concentrations [49]. Moreover, these PEGylated NPRs did not provoke significant biochemical or hematological differences between untreated control mice and nanoparticles-treated mice, which is in accordance to our results.

Gold NPs are traditionally considered inert and thus resistant to degradation in vivo. However, they can be slowly dissolved as cells contain thiols (i.e. glutathione) that can strongly bind to the Au surface, and under certain conditions pull out gold atoms from the NP surface using the surface-bound ligands [50, 51]. Supporting this hypothesis we have observed that although NPR-PTG were not detected in urine by ICP-MS, the fluorophore attached to the surface of the NPR was found just after $24 \mathrm{~h}$. This would mean that the ligand was removed from the NPR once injected and then excreted in the urine. These results are in accordance to those of Kreyling et al. who employing different isotopes to selectively label the core and the shell of AuNPs, found that the Au core was accumulated in the liver, while rest of the coating appeared in urine [34]. The fluorophore excretion could also explain the observed difference in the weight of the kidneys $72 \mathrm{~h}$ after injection. Renal cleareance could produce inflammation increasing the relative weight of the kidney [52] which in the present study is a transient effect that could be related with the fluorophore excretion due to the fact that the kidneys recovered their usual weight 4 months after injection.

Together, the quantification of Au by ICP-MS and the results of STEM imaging suggest that liver tissue is able to slowly degrade and eliminate NPRs. In a recent study with iron oxide coated $\mathrm{Au}$ nanoparticles it was found that after the dissolution of iron oxide crystals $\mathrm{Au}$ particles degraded to form progressively smaller particles that tend to self-assemble together [53]. In a study with $40 \mathrm{~nm} \mathrm{Au}$ nanoparticles injected i.v. $\left(4.5 \cdot 10^{10}\right.$ particles/mouse) it was found that a fraction of gold-loaded cells in the liver gradually decreased to about one fifth after 6 months [54]. Moreover, over time it was found that an increasing part of the total amount of Au nanoparticles in the liver was contained in fewer cells which accumulated in growing clusters. Therefore our observations of small alterations in the volume of the cytoplasm of the hepatocytes and an increase in the number or vacuoles in most of the mice may also suggest ongoing degradation process However, a longer study period (e.g. one year) and more detailed degradation analysis will be required to investigate if NPRs are completely eliminated by liver or in contrast this accumulation results toxic for this organ.

\section{Conclusions}

The physicochemical properties of NPRs highlight them as promising agents for bioapplications including imaging and selective drug delivery. However, the potential secondary effects that could be triggered by NPRs following in vivo administration require special attention. Before performing in vivo toxicity experiments in animal models, the in vitro tests in primary and transformed cells are a must to avoid unnecessary animal usage in case NPRs present high cell toxicity and to design properly the in vivo experiments and the parameters to be tested. Moreover, the effect of NPRs on cellular viability is currently a hotly debated issue that so far has not been clarified. We show here that NPR internalization by a panel of mouse and human transformed and primary cells affect mitochondrial function and ROS generation, yet do not compromise cell viability as shown by clonogenic assays. Thus, our data indicate that assessment of the toxic effects of NPRs in vitro requires of multiparametric analyses of different cell functions before a relevant conclusion could be reached. Other reports have shown that NPR uptake does indeed modify mitochondrial function and generates ROS [22]; however, in some cases these changes compromised cell viability [22, 55, 56] but not in others [24, 42, 57]. In these cases the type of NPRs and cells tested may be the cause of these apparent contradictory findings. Our in vitro results using transformed and primary cells are commensurate with the in vivo findings, which indicate that large $(150 \mathrm{~nm})$ gold NPRs are non-toxic when administered intravenously even after four months; although small amounts do accumulate in the liver and spleen and could be associated to small alterations in the liver which nevertheless do not seem to affect the animal health. These are the first analyses of the in vivo toxic effects including inflammatory response of gold NPRs supporting the use of this type of NPs for in vivo biomedical applications. However before gold NPRs could be introduced in clinical settings more detailed studies including other toxicity parameters like a more detailed immunogencity study and genotoxicity and using different coatings, administration routes and prolonged study times will be required.

\section{Methods \\ Synthesis and characterization of the gold NPRs}

All chemicals and solvents were of analytical grade purchased from Sigma (Sigma-Aldrich, St. Louis, MO, USA) and used as supplied, without further purification. Pure water was used throughout by passing water through a Milli-Q Academic purification set (Millipore Sigma, Billerica, MA, USA).

To synthesize NPRs, prior to use, all the glass material was washed with aqua regia and rinsed thoroughly with MilliQ water. Then, $100 \mathrm{~mL}$ of $2 \mathrm{mM}$ (aq.) $\mathrm{HAuCl}_{4}$ and $120 \mathrm{~mL}$ of freshly prepared $0.5 \mathrm{mM} \mathrm{N} \mathrm{Na}_{2} \mathrm{~S}_{2} \mathrm{O}_{3}$ were mixed, under mild magnetic stirring conditions for 9 min using c-mag hs stirrer (Ika, Wilmington, NC, USA) (speed 2 of 5 which corresponds to $500 \mathrm{rpm}$ ), prior to a second addition of $50 \mathrm{~mL}$ of $0.5 \mathrm{mM} \mathrm{Na}_{2} \mathrm{~S}_{2} \mathrm{O}_{3}$. This will 
produce gold NPRs of ca. $150 \mathrm{~nm}(146.2 \pm 32.4 \mathrm{~nm}$, cf. Fig. S1 in the Additional file 1) of length with possessing a localised surface plasmon resonance (LSPR) band maximum in the LSPR in the range at $1050 \mathrm{~nm}$ (NIR range) [7]. These NPRs possess an edge length of ca. $150 \mathrm{~nm}$ and height of $10 \mathrm{~nm}$ and were characterized by UVVis spectroscopy and scanning electron microscopy (Additional file 1: Figure S1) as follows. All samples were measured in aqueous suspension at room temperature using a Varian Cary 50 UV-visible spectrometer (Varian, Corona, CA, USA) over the range of 200$1100 \mathrm{~nm}$ in $1 \mathrm{~cm}$ quartz cuvettes. Scanning Electron Microscopy (SEM): a single drop of the aqueous solution of the NPRs was placed onto a silicon wafer and SEM analysis were performed using a Inspect $\mathrm{F}$ instrument (FEI, Hilsboro, OR, USA) operated at $30 \mathrm{kV}$. To increase their colloidal stability, NPRs were functionalized with polyethylenglycol (PEG) chain (HS- $\mathrm{C}_{2} \mathrm{H}_{4}$-CONH-PEG-O$\mathrm{C}_{3} \mathrm{H}_{6}-\mathrm{COOH}$ ) M.W. $5 \mathrm{kDa}$, (Rapp-Polymer) and resuspended in MilliQ water. In general, $1 \mathrm{mg}$ of thiolated PEG was added to $10 \mathrm{~mL}$ of NPRs. Then, the $\mathrm{pH}$ of the solution was raised up to 12.0 using $2 \mathrm{M} \mathrm{(aq)} \mathrm{NaOH}$. After overnight incubation, NPRs were cleaned of the free PEG by centrifugation (twice for $15 \mathrm{~min}$ at $10000 \mathrm{rpm}$ ) and the pellet was resuspended in MilliQ water.

NPRs were derivatised with tetramethylrhodamine-5carboxamide cadaverine (5-TAMRA cadaverine); absorption/emission $=545 / 576 \mathrm{~nm}$ (Anaspec, Fremont, CA, USA), glucose (4-aminophenyl $\beta$-D- glucopyranoside) or both ligands. $1 \mathrm{mg}$ NPR were incubated with $1 \mathrm{mg}$ of 1-Ethyl-3-(3-dimethylaminopropyl) carbodiimide hydrochloride (EDC) and $3 \mathrm{mg}$ of N-hydroxysulfosuccinimide (Sulfo-NHS) in $1.5 \mathrm{~mL}$ of $50 \mathrm{mM}$ 2-(N-morpholino) ethanesulfonic acid (MES) buffer at $\mathrm{pH} 6$ for $20 \mathrm{~min}$ at $37{ }^{\circ} \mathrm{C}$. Activated NPRs were then incubated overnight with $10 \mu \mathrm{g}$ of TAMRA (NPR-PT); $40 \mu \mathrm{g}$ of glucose (NPR-PG); or a combination of $10 \mu \mathrm{g}$ of TAMRA and $40 \mu \mathrm{g}$ of glucose (NPR-PTG). Functionalized NPRs were then subjected to centrifugal precipitation (twice for $15 \mathrm{~min}$ at $10000 \mathrm{rpm}$ ) to remove excess reagents and the pellets were resuspended first in MilliQ water.

NPRs were prepared using endotoxin free water and filtered in using $0.22 \mu \mathrm{m}$ syringe cellulose filters in order to render them sterile. All the experiments were carried out under sterile conditions working with microbiological class II safety cabinets.

NPRs were characterised by UV-Vis and SEM as previous described. Zeta potential measurements were done using a ZetaPALS (Brookhaven, Holtsville, NY, USA). Fluorescence measurements were performed with a LS 55 Fluorescence Spectrometer, $120 \mathrm{~V}$ (PerkinElmer, Waltham, MA, USA). Data shown in Additional file 1: Figures. S1-S4.

By using ICP-MS (explained in more detail in animal section) the $\mathrm{Au}$ concentration in the stock was quantified. The concentration value was used to determine the extinction coefficient at the maximum of absorbance by plotting the absorbance (at the maximum, LSPR) versus the concentration of different NPs solutions. Therefore, the concentration of the stock solutions could always be estimated by measuring the UV-Vis of the solutions and was always indirectly based in ICP-MS results.

\section{Cell culture}

For cell culture the following reactives were used; DMEM, MEM, RPMI1640, Trypsin-EDTA $0.25 \%$ were purchased from PAN biotech (PAN biotech, Aidenbach, Germany). Serum (FBS) (Lonza, Basel, Switzerland). GlutaMAX and pyruvate (Sigma-Aldrich, St. Louis, MO, USA). Penicillin-Streptomycin, non essential aminoacids and sodium bicarbonate (Gibco, Gaithersburg, MD, USA).

SV40 transformed mouse embrionary fibroblasts (MEFs) were kindly provided by Dr. Christoph Borner (Institute of Molecular Medicine and Cell Research, Centre for Biochemistry and Molecular Research, Freiburg) and mouse melanoma (B16) and mouse fibrosarcoma (MC57G) were kindly provided by Markus M Simon (Max-Planck Institute for Immunobiology, Freiburg). Human cervix carcinoma (HeLa), human pancreas carcinoma (MiaPaca) and human lung carcinoma (A549) were acquired from ATCC cultures. MEF, B16, HeLa and MiaPaca cells were cultured in DMEM supplemented with 10\% FBS. MC57G cells in MEM supplemented with 10\% FBS. A549 cells in DMEM supplemented with $10 \% \mathrm{FBS}, 2.2 \mathrm{~g} / \mathrm{L} \mathrm{NaHCO}_{3}, 100 \mathrm{mg} / \mathrm{L}$ pyruvate and non-essential amino acids. All of them were cultured in an incubator at $37^{\circ} \mathrm{C}$ with $5 \% \mathrm{CO}_{2}$.

Human peripheral-blood mononuclear cells (PBMCs) were obtained from the blood of 3 healthy donors by density gradient centrifugation using Ficoll-Paque (GEHealthcare, Little Chalfont, UK). Blood samples were provided by blood and tissue bank of Aragón. This study has been approved by the Ethics Committee for Clinical Research of Aragon (CEICA).

Mouse Bone Marrow-derived Macrophages (BMDMs) were differentiated from bone marrow cells as previously described [58]. Briefly, cells were obtained from femurs of 3 C57BL10 mice 6-12 weeks of age by flushing the bone marrow with DMEM and cells were differenciated in BMDM medium (DMEM supplemented with 10\% FBS and $5 \% \mathrm{HS}$ both decomplemented, $2 \mathrm{mM}$ GlutaMAX and $10 \%$ of L929 cell culture supernatant as a source of M-CSF) for 6 days. This protocol generates inflammatory $\mathrm{CD}_{11} \mathrm{~b}^{+} \mathrm{CD} 11 \mathrm{c}^{-}$macrophages with a M1 phenotype as analysed by its ability to produce IL1 $\beta$ and TNF $\alpha$ in response to LPS and ATP (data not shown).

\section{Confocal microscopy}

$2 \cdot 10^{5}$ cells were seeded in 24 well plates on $13 \mathrm{~mm}$ diameter cover glasses $\left(10^{5}\right.$ cells $\left./ \mathrm{cm}^{2}\right)$ (Electron 
microscopy science, Hatfield, PA, USA) overnight to allow attachment and treated with 0, 25, 50, 100 and $200 \mu \mathrm{g} / \mathrm{mL}$ NPR-PT and NPR-PTG for $24 \mathrm{~h}$ in $1 \mathrm{~mL}$, final volumen. Cells on coverslips were washed with PBS and fixed with $4 \%$ paraformaldehyde solution in PBS for $20 \mathrm{~min}$ at $4{ }^{\circ} \mathrm{C}$. Fixed cells were mounted on a drop of fluoromount-G (SouthernBiotech, Birmingham, AL, USA) containing $2 \mu \mathrm{g} / \mathrm{mL}$ Hoechst 33,342 (Invitrogen, Carlsbad, USA). Afterward, the cells were analyzed by confocal microscopy (60× objective). Fluorescence images were taken at room temperature on a confocal microscope (Olympus FV10-i Oil Type) using the same settings for all the cell lines. The software FV10i-SW was used for minor adjustments to background and image overlay.

\section{Analysis of pro-apoptotic processes by flow cytometry} Cells $\left(2 \cdot 10^{5} \mathrm{cel} / \mathrm{mL}\right)$ were resuspended in culture medium, seeded at a $10^{5}$ cells $/ \mathrm{cm}^{2}$ and treated with the NPRs at different concentrations $0,25,50,100$ y $200 \mu \mathrm{g} /$ $\mathrm{mL}$ for $48 \mathrm{~h}$ at $37{ }^{\circ} \mathrm{C}$ and $5 \% \mathrm{CO}_{2}$ and the different apoptotic parameters were tested by flow cytometry with a FACS Calibur (BD, Franklin Lakes, NJ, United States) and CellQuests software. ROS generation was analysed using dihydroethidine (2HE, $2 \mu \mathrm{M})$ (Invitrogen, Carlsbad, USA), $\Delta \psi_{\mathrm{m}}$ was measured with the fluorescent probe 3,3-dihexyloxacarbocyanine iodide $\left(\mathrm{DiOC}_{6}\right) 10 \mathrm{nM}$ (Invitrogen, Carlsbad, USA) and PS exposure and 7AAD uptake was analyzed using annexinV-DY634 and 7AAD at 1/100 dilution (Inmunostep, Salamanca, Spain), as follows. Briefly, cells were tripsinyzed, centrifugated $300 \mathrm{xg}$ for $5 \mathrm{~min}$ and incubated with the probe for $20 \mathrm{~min}$ at room temperature, in cell culture medium for $2 \mathrm{HE}$ and $\mathrm{DiOC}_{6}(3)$ or in annexin binding buffer (Inmunostep, Salamanca, Spain) for annexin V. [58].

\section{Clonogenic survival assay}

Clonogenic assay or colony formation assay is an in vitro cell survival assay based on the ability of a single cell to grow and generate a colony. $48 \mathrm{~h}$ after treatment, cells were trypsinized and 100 cells were seeded per well in a final volume of $3 \mathrm{~mL}$ in a six-well plate $\left(10\right.$ cells $\left./ \mathrm{cm}^{2}\right)$. Cells were allowed to grow during 10 days and after that time, medium was removed and cell colonies were counted after fixing and colouring them for 20 min with a mixture of glutaraldehyde $(6.0 \% \mathrm{v} / \mathrm{v})$ and crystal violet $(0.5 \% w / v)$ at room temperature.

\section{Animal experimentation}

All the experiments involving animals were made according to the law RD53/2013 and approved by the Ethics Committee for Animal Research from University of Zaragoza that is an accreditated animal-welfare body. All the experiments were performed according to the institutional animal use and care regulation of the Centro de Investigación
Biomédica de Aragón (CIBA; Zaragoza, Spain). The animals were purchased from the CIBA centre and fed a standard diet ad libitum throughout the experiments. Pathogen-free 6 week old Swiss mice were randomly divided into 2 different groups: mice injected with NPR-PTG and control group where PBS was injected. To reach statistically significant results, 2 independent experiments were performed. Each group (control and treated) consisted of 10 animals, 5 male and 5 female, in order to discard sexualbiased results. NPR-PTG were suspended in $100 \mu \mathrm{L}$ of PBS and injected intravenously in the tail vein at dose of $6 \mu \mathrm{g}$ NPR-PTG per g. This dose corresponds to approximately 75-100 $\mu \mathrm{g}$ NPR-PTG/mL blood in the moment of administration, which is in accordance with the concentrations analysed in the experiments in vitro. Mice were sacrificed $72 \mathrm{~h}$ and 4 months after the injection in $\mathrm{CO}_{2}$ gas chamber. Subsequently the blood has been collected by cardiac puncture using $10 \%$ of sodium citrate as anticoagulant for plasma separation via centrifugation ( $15 \mathrm{~min}, 2000 \mathrm{x}$ g). ALT (alanine aminotransferase), and CK (creatine kinase), activities was measured according to the IFCC recommendations, by means of the decrease (ALT) or increase (CK) of absorbance at $340 \mathrm{~nm}$. Determination of LDH (lactate dehydrogenase) activity was measured by the transformation of lactate to piruvate, measuring the increase of absorbance at $340 \mathrm{~nm}$. Creatinine concentrations were determined by the Jaffé method. All measurements were carried out using an automated analyzer Cobas c501 (Roche Diagnostics, Indianapolis, IN, USA).

Levels of IFNY and TNFo were quantified with their respective "Ready-Set-Go" ELISA kit (eBioscience, San Diego, CA USA) following manufacturer's instructions for which $100 \mu \mathrm{L}$ serum were needed per each cytokine analyzed in a 96 well plate format. The detection method is based on the enzyme Pre-titrated Avidin HRP (horseradish peroxidase) measuring absorbance at $450 \mathrm{~nm}$ and $570 \mathrm{~nm}$ in a plate reader Synergy ${ }^{\text {TM }}$ HT (BioTek, Winooski, VT, USA). The results were obtained substrating the values of 570 from those of 450 (Abs ${ }_{450}$-Abs 570 ).

Finally liver, spleen, kidneys, heart, lungs, thymus and reproductive organs were excised and prepared for, histopathological tissue examination, TEM, STEM and ICP-MS measurements. In the case of short term study $(72 \mathrm{~h})$ three mice from NPR-PTG group and one from control were placed in a metabolic cage enabling urine samples collection every $24 \mathrm{~h}$.

\section{Histology examination of haematoxylin and eosin stained tissue sections}

For pathological examination of the organs, pieces of the excised organs were fixed with $\mathrm{pH}$ 7.4 phosphate-buffered $4 \%$ paraformaldehyde during $24 \mathrm{~h}$ at $4{ }^{\circ} \mathrm{C}$ and processed in mesh cassettes (Mesh Biopsy Cassette) using a standard protocol in an automatic tissue processor; Tissue-Tek 
Xpress $\times 50$ (Sakura Fineteck, Torrance, CA, USA). The preparation of the blocks was carried out with the block making unit Leica EG1150 (Leica Bioscience, Wetzlar, Germany) after which the blocks were solidified on a cold plate. Samples were embedded in paraffin, sectioned at $3 \mu \mathrm{m}$ thick (Rotary microtome Leica RM2255) and placed in a tempered bath where they were collected with Superfrost slides (Dako Flex IHC Microscope Slides; ref.: K8020) (Angilent technologies, Santa Clara, CA, USA). The slides were placed in vertical racks and allowed to dry in an oven. After dewaxing and hydration process, the samples were stained with hematoxylin and eosin ready-touse Dako (Agilent, Santa Clara, CA, USA) and mounted with permanent mounting medium DPX.

\section{TEM and STEM characterization of organs}

For electron microscopic analysis, the excised organs were cut into $1 \mathrm{~mm}^{3}$ pieces and fixed with $2.5 \%$ glutaraldehyde/2\% paraformaldehyde in $0.1 \mathrm{M}$ sodium phosphate buffer at $\mathrm{pH} 7.4$ for $24 \mathrm{~h}$ at room temperature and subsequently stored for 5 days at $4{ }^{\circ} \mathrm{C}$. Thereafter the samples were washed for $30 \mathrm{~min}$ four times with sodium phosphate buffer, post-fixed with $2 \%$ osmium, rinsed, dehydrated and embedded in Durcupan resin Fluka (Sigma-Aldrich, St. Louis, MO, USA). Semithin sections $(1.5 \mu \mathrm{m})$ were cut with an Ultracut UC-6 (Leica, Wetzlar, Germany) and stained lightly with $1 \%$ toluidine blue. Finally, ultra-thin sections $(0.08 \mu \mathrm{m})$ were cut with a diamond knife, stained with lead citrate (Reynolds solution) and examined under a $300 \mathrm{kV}$ transmission electron microscope FEI Tecnai F30 enabling working in STEM mode and performing X-Ray Microanalysis (EDS) (FEI Europe, Eindhoven, The Netherlands).

\section{ICP-MS}

Organs were washed in PBS buffer and frozen in liquid nitrogen upon collection. Following, they were thawed and washed trice in distillate water. All samples were lyophilized using Laboratory Freeze Dryer CRYODOS (Telstar Industrial, S.L., Terrassa, Spain), weighted, placed in porcelain crucibles and burned in a Mini Muffle Furnace (Nabertherm $\mathrm{GmbH}$, Lilienthal, Germany) at $600{ }^{\circ} \mathrm{C}$ during $45 \mathrm{~min}$. To the cooled ashes $200 \mu \mathrm{L}$ of piranha solution $(>85 \%$ sulphuric acid and $>50 \%$ hydrogen peroxide) were added and the solution was left for $10 \mathrm{~min}$. Following, $200 \mu \mathrm{L}$ of aqua regia was added, the solution was transferred to a $15 \mathrm{~mL}$ centrifuge tube (TPP Techno Plastic Products AG, Trasadingen, Switzerland) and heated at $70{ }^{\circ} \mathrm{C}$ for one hour using a thermoblock (Thermo Fisher, Massachusetts, USA). For ICP analysis, the content of acids has to be between 1 and $5 \%$. Therefore, the samples were centrifuged for $5 \mathrm{~min}$ to eliminate the ashes, trasfered to a $50 \mathrm{~mL}$ centrifuge tube (TPP Techno Plastic Products AG,
Trasadingen, Switzerland) and diluted to the final volume of $20 \mathrm{~mL}$ ( $2 \%$ of acids) using graduated cylinder.

The quantitative $\mathrm{Au}$ analysis was performed by using ICP-MS 7700× (Agilent Technologies, Sta Clara, CA, USA). ICP-MS was used for Au determination using a MicroMist micro-uptake glass concentric nebulizer (Glass Expansion, West Melbourne, Victoria, Australia). In order to reduce $\mathrm{MO}^{+}$formation in the plasma, the spray chamber was peltier cooled at $2{ }^{\circ} \mathrm{C}$. A standard quartz torch with $2.5 \mathrm{~mm}$ internal diameter injector was used. Finally, standard nickel cones (sample and skimmer) were used. The optimization of the ICP-MS conditions was achieved by adjusting the torch position and tuning for reducing oxide and doubly charged ion formation with a standard tuning solution containing $1.0 \mu \mathrm{g} \mathrm{L}{ }^{-1}$ of ${ }^{7} \mathrm{Li}$, ${ }^{24} \mathrm{Mg},{ }^{59} \mathrm{Co},{ }^{89} \mathrm{Y},{ }^{140} \mathrm{Ce}$ and ${ }^{205} \mathrm{Tl}$ in $1.0 \% \mathrm{HNO}_{3}$. This equipment includes a collision cell (He gas, ORS3 system, Agilent Technologies $($ ) ) for discriminate spectral interferences with high performance for all the trace metals considered in here. The calibration curve comprises a linear range from 0.01 to $20 \mathrm{ppb}$.

The precision of the analysis is $<10 \%$. Other parameters such as accuracy and recovery could not be determined without knowing the exact Au content in the sample before measuring it.

All the analysis were performed in the Servicio Central Analisis de Bizkaia (Universidad del Pais Vasco).

\section{Statistical analysis}

All data are presented as the mean \pm standard deviation (SD). Significant differences between groups were evaluated by two-way ANOVA with Bonferroni post-test using GraphPad Prism 5.0 (GraphPad 339 Software, CA, USA). ${ }^{*} p<0.05,{ }^{* * *} p<0.01,{ }^{* * * *} p<0.001$.

\section{Additional file}

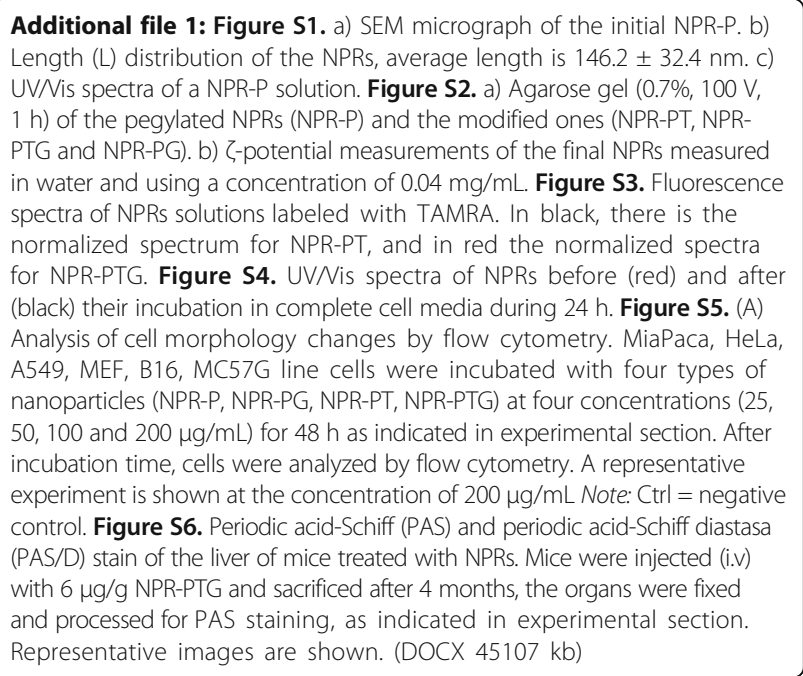




\section{Abbreviations}

2HE: dihydroethidine; AnnV: Annexin-V; NPR: Nanoprisms; NPR-P: PEGylated nanoprisms; NPR-PG: PEGGlylated nanoprisms modified with glucose; NPRPT: PEGylated nanoprisms modified with rhodamine; NPR-PTG: PEGGlylated nanoprisms modified with glucose and rhodamine; NPs: nanoparticles; PBMCs: Peripheral blood mononuclear cells; PEG: Polyethylene glycol; PS: Phosphatydylserine; PTP: Permeability transition pore; ROS: Reactive oxygen species; SEM: Scanning electron microscopy; SSC: Side-scattered light; $\Delta \Psi_{\mathrm{m}}$ : mitochondrial membrane potential

\section{Acknowledgements}

We wish to thank The Advanced Microscopy Laboratory (INA-Universidad de Zaragoza) for access to their instrumentation and expertise and the SCAB (Central Analysis Service Bizkaia) for ICP-MS analysis. We would like to acknowledge the use of Servicios Cientifico-Tecnicos (SCT) del CIBA (Instituto Aragones de Ciencias de la Salud, Universidad de Zaragoza, Fundacion IIS Aragón).

\section{Funding}

This work was supported by the MAT2011-26851-CO2-01, MAT2011-26851CO2-02, SAF2011-25390, SAF2014-54763-C2-1-R and SAF2014-54763-C2-2$R$ - projects of the Spanish Ministry of Science and Innovation, PIE201460I019 (CSIC), the grant ERC-Starting Grant 239,931-NANOPUZZLE project, ERC-PoC 754609 HOTFLOW project, Fondo Social Europeo (FSE; Gobierno de Aragón) and the Consellería de Cultura, Educación e Ordenación Universitaria (Centro singular de investigación de Galicia accreditation 2016-2019, ED431G/09) and the European Regional Development Fund (ERDF).

P.d.P., J.M.F., J.P. thank ARAID for financial support, B.P. thanks the Alexander von Humboldt Foundation for a fellowship and M.M. acknowledges financial support from European Union's Horizon 2020 research and innovation programme under the Marie Skłodowska-Curie grant agreement No. 660228.

\section{Availability of data and materials}

Data sharing not applicable to this article as no datasets were generated or analysed during the current study.

\section{Authors' contributions}

M.P. performed incubation of cells with NPRs, studies of confocal microscopy, analysed cell death and viability. M.P., M.M. and G.S. designed, carried out and analysed the in vivo studies and drafted the manuscript. P.d.P. participated in the design of the study and in the evaluation of the results and wrote the first draft of the manuscript. P.d.P and S.G.M. carried out the synthesis and functionalisation of gold NPRs. M.A. carried out the cytokines analysis. B.P. characterised the physicochemical properties of the gold NPRs. S.M performed and analysed the blood biochemical tests. M.H. performed the anatomic pathology tests. E.M.G. participated in the design and coordination of the study. J.M.F. conceived of the study, its design and coordination. J.P. conceived of the study, its design and coordination and wrote the end version of the manuscript. All authors read and approved the final manuscripts.

\section{Ethics approval}

Blood samples were provided by blood and tissue bank of Aragón. This study has been approved by the Ethics Committee for Clinical Research of Aragon (CEICA).

All the experiments involving animals were made according to the law RD53/ 2013 and approved by the Ethics Committee for Animal Research from University of Zaragoza that is an accreditated animal-welfare body. All the experiments were performed according to the institutional animal use and care regulation of the Centro de Investigación Biomédica de Aragón (CIBA; Zaragoza, Spain).

\section{Consent for publication}

Not applicable.

\section{Competing interests}

The authors declare that no competing interests exist.

\section{Publisher's Note}

Springer Nature remains neutral with regard to jurisdictional claims in published maps and institutional affiliations.

\section{Author details}

'Departamento de Bioquímica y Biología Molecular y Celular, Facultad de Ciencias, Universidad de Zaragoza, 50009 Zaragoza, Spain. ${ }^{2}$ Instituto de Investigación Sanitaria de Aragón (IIS Aragón), Centro de Investigación Biomédica de Aragón (CIBA), Universidad de Zaragoza, 50009 Zaragoza, Spain. ${ }^{3}$ Instituto Universitario de Nanociencia de Aragón (INA), Universidad de Zaragoza, 50018 Zaragoza, Spain. ${ }^{4}$ Institute of Applied Sciences and Intelligent Systems-CNR, Via Campi Flegrei, 34, 80078 Pozzuoli, Italy. ${ }^{5}$ Fundación Instituto Universitario de Nanociencia de Aragón (FINA), Universidad de Zaragoza, 50018 Zaragoza, Spain. ${ }^{6} \mathrm{CIBER}$ in Bioengineering, Biomaterials and Nanomedicine (CIBER-BBN), Zaragoza, Spain. ${ }^{7}$ Centro Singular de Investigación en Química Biológica y Materiales Moleculares (CiQUS) y Departamento de Física de Partículas, Universidade de Santiago de Compostela, 15782 Santiago de Compostela, Spain. ${ }^{8}$ Departamento de Bioquímica clínica. H.C.U. Lozano Blesa, 50009 Zaragoza, Spain.

${ }^{9}$ Departamento de Patología Animal, Facultad de Veterinaria, Universidad de Zaragoza, 50009 Zaragoza, Spain. ${ }^{10}$ Instituto de Ciencia de Materiales de Aragón, CSIC-Universidad de Zaragoza, Zaragoza, Spain. ${ }^{11}$ Instituto de Carboquímica ICB-CSIC, 50018 Zaragoza, Spain. ${ }^{12}$ Departamento de Microbiología, Medicina Preventiva y Salud Pública, Facultad de Medicina, Universidad de Zaragoza, 50009 Zaragoza, Spain. ${ }^{13}$ Aragón I+D Foundation (ARAID), Gobierno de Aragón, Zaragoza, Spain.

Received: 2 February 2017 Accepted: 17 October 2017 Published online: 26 October 2017

\section{References}

1. Holzinger M, Le Goff A, Cosnier S. Nanomaterials for biosensing applications: a review. Front Chem. 2014:2:63.

2. Verma J, Lal S, Van Noorden CJ. Nanoparticles for hyperthermic therapy: synthesis strategies and applications in glioblastoma. Int J Nanomedicine. 2014;9:2863-77.

3. Pelaz B, Alexiou C, Alvarez-Puebla RA, Alves F, Andrews AM, Ashraf S, Balogh $L P$, Ballerini L, Bestetti A, Brendel C, et al. Diverse applications of nanomedicine. ACS Nano. 2017:11:2313-81.

4. Abadeer NS, Murphy CJ. Recent progress in cancer thermal therapy using gold nanoparticles. J Phys Chem C. 2016;120:4691-716.

5. Alkilany AM, Thompson LB, Boulos SP, Sisco PN, Murphy CJ. Gold nanorods: their potential for photothermal therapeutics and drug delivery, tempered by the complexity of their biological interactions. Adv Drug Deliv Rev. 2012; 64:190-9.

6. Huschka R, Barhoumi A, Liu Q, Roth JA, Ji L, Halas NJ. Gene silencing by gold nanoshell-mediated delivery and laser-triggered release of antisense oligonucleotide and siRNA. ACS Nano. 2012;6:7681-91.

7. Pelaz B, Grazu V, Ibarra A, Magen C, del Pino P, de la Fuente JM. Tailoring the synthesis and heating ability of gold nanoprisms for bioapplications. Langmuir. 2012;28:8965-70.

8. Perez-Hernandez M, Del Pino P, Mitchell SG, Moros M, Stepien G, Pelaz B, Parak WJ, Galvez EM, Pardo J, de la Fuente JM. Dissecting the molecular mechanism of apoptosis during photothermal therapy using gold nanoprisms. ACS Nano. 2015;9:52-61.

9. Albanese A, Sykes EA, Chan WC. Rough around the edges: the inflammatory response of microglial cells to spiky nanoparticles. ACS Nano. 2010;4:2490-3.

10. Arvizo RR, Bhattacharyya S, Kudgus RA, Giri K, Bhattacharya R, Mukherjee P. Intrinsic therapeutic applications of noble metal nanoparticles: past, present and future. Chem Soc Rev. 2012;41:2943-70.

11. Dreaden EC, Alkilany AM, Huang X, Murphy CJ, El-Sayed MA. The golden age: gold nanoparticles for biomedicine. Chem Soc Rev. 2012;41:2740-79.

12. Pelaz B, Charron G, Pfeiffer C, Zhao Y, de la Fuente JM, Liang XJ, Parak WJ, Del Pino P. Interfacing engineered nanoparticles with biological systems: anticipating adverse nano-bio interactions. Small. 2013;9:1573-84.

13. Qin Z, Bischof JC. Thermophysical and biological responses of gold nanoparticle laser heating. Chem Soc Rev. 2012;41:1191-217.

14. Rivera-Gil P, Jimenez de Aberasturi D, Wulf $V$, Pelaz B, del Pino P, Zhao Y, de la Fuente JM, Ruiz de Larramendi I, Rojo T, Liang XJ, Parak WJ. The challenge to relate the physicochemical properties of colloidal nanoparticles to their cytotoxicity. Acc Chem Res. 2013:46:743-9.

15. Nel AE, Madler L, Velegol D, Xia T, Hoek EM, Somasundaran P, Klaessig F, Castranova V, Thompson M. Understanding biophysicochemical interactions at the nano-bio interface. Nat Mater. 2009;8:543-57. 
16. Arora S, Rajwade JM, Paknikar KM. Nanotoxicology and in vitro studies: the need of the hour. Toxicol Appl Pharmacol. 2012;258:151-65.

17. Nel A, Xia T, Madler L, Li N. Toxic potential of materials at the nanolevel. Science. 2006;311:622-7.

18. Huhn D, Kantner K, Geidel C, Brandholt S, De Cock I, Soenen SJ, Rivera Gil P, Montenegro JM, Braeckmans K, Mullen K, et al. Polymer-coated nanoparticles interacting with proteins and cells: focusing on the sign of the net charge. ACS Nano. 2013;7:3253-63.

19. Soenen S, Rivera-Gil P, Montenegro J, Parak W, Smedt SD, Braeckmans K. Cellular toxicity of inorganic nanoparticles: common aspects and guidelines for improved nanotoxicity evaluation. Nano Today. 2011;6:446-65.

20. Tian F, Clift MJ, Casey A, Del Pino P, Pelaz B, Conde J, Byrne HJ, RothenRutishauser B, Estrada G, de la Fuente JM, Stoeger T. Investigating the role of shape on the biological impact of gold nanoparticles in vitro. Nanomedicine (Lond). 2015;10:2643-57.

21. Xia T, Kovochich M, Liong M, Zink Jl, Nel AE. Cationic polystyrene nanosphere toxicity depends on cell-specific endocytic and mitochondrial injury pathways. ACS Nano. 2008;2:85-96.

22. Soenen SJ, Manshian B, Montenegro JM, Amin F, Meermann B, Thiron T, Cornelissen M, Vanhaecke F, Doak S, Parak WJ, et al. Cytotoxic effects of gold nanoparticles: a multiparametric study. ACS Nano. 2012;6:5767-83.

23. Manshian BB, Pfeiffer C, Pelaz B, Heimerl T, Gallego M, Moller M, del Pino P, Himmelreich U, Parak WJ, Soenen SJ. High-content imaging and gene expression approaches to unravel the effect of surface functionality on cellular interactions of silver nanoparticles. ACS Nano. 2015;9:10431-44.

24. Lipka J, Semmler-Behnke M, Sperling RA, Wenk A, Takenaka S, Schleh C, Kissel T, Parak WJ, Kreyling WG. Biodistribution of PEG-modified gold nanoparticles following intratracheal instillation and intravenous injection. Biomaterials. 2010;31:6574-81.

25. Niidome T, Yamagata M, Okamoto Y, Akiyama Y, Takahashi H, Kawano T, Katayama Y, Niidome Y. PEG-modified gold nanorods with a stealth characte for in vivo applications. J Control Release. 2006;114:343-7.

26. Lal S, Clare SE, Halas NJ. Nanoshell-enabled photothermal cancer therapy: impending clinical impact. Acc Chem Res. 2008;41:1842-51.

27. Baffou GQR, Girard C. Heat generation in plasmonic nanostructures: influence of morphology. Appl Phys Lett. 2009;94:153109.

28. Bao C, Beziere N, del Pino P, Pelaz B, Estrada G, Tian F, Ntziachristos V, de la Fuente JM, Cui D. Gold nanoprisms as optoacoustic signal nanoamplifiers for in vivo bioimaging of gastrointestinal cancers. Small. 2013;9:68-74.

29. Polo E, del Pino P, Pelaz B, Grazu V, de la Fuente JM. Plasmonic-driven thermal sensing: ultralow detection of cancer markers. Chem Commun (Camb). 2013;49:3676-8.

30. Moros M, Hernaez B, Garet E, Dias JT, Saez B, Grazu V, Gonzalez-Fernandez A, Alonso C, de la Fuente JM. Monosaccharides versus PEG-functionalized NPs: influence in the cellular uptake. ACS Nano. 2012;6:1565-77.

31. Kalyanaraman B, Darley-Usmar V, Davies KJ, Dennery PA, Forman HJ, Grisham MB, Mann GE, Moore K, Roberts $\sqcup$ 2nd, Ischiropoulos H. Measuring reactive oxygen and nitrogen species with fluorescent probes: challenges and limitations. Free Radic Biol Med. 2012;52:1-6.

32. Zielonka J, Kalyanaraman B. Hydroethidine- and MitoSOX-derived red fluorescence is not a reliable indicator of intracellular superoxide formation: another inconvenient truth. Free Radic Biol Med. 2010;48:983-1001.

33. Arias MA, Jimenez de Bagues MP, Aguilo N, Menao S, Hervas-Stubbs S, de Martino A, Alcaraz A, Simon MM, Froelich CJ, Pardo J. Elucidating sources and roles of granzymes $\mathrm{a}$ and $\mathrm{B}$ during bacterial infection and sepsis. Cell Rep. 2014:8:420-9.

34. Kreyling WG, Abdelmonem AM, Ali Z, Alves F, Geiser M, Haberl N, Hartmann R, Hirn S, de Aberasturi DJ, Kantner K, et al. Vivo integrity of polymer-coated gold nanoparticles. Nat Nanotechnol. 2015;10:619-23.

35. Puntes $V$. Design and pharmacokinetical aspects for the use of inorganic nanoparticles in radiomedicine. Br J Radiol. 2016;89:20150210.

36. Li Y, Italiani P, Casals E, Valkenborg D, Mertens I, Baggerman G, Nelissen I, Puntes VF, Boraschi D. Assessing the Immunosafety of engineered nanoparticles with a novel in vitro model based on human primary monocytes. ACS Appl Mater Interfaces. 2016;8:28437-47.

37. Moros M, Pelaz B, Lopez-Larrubia P, Garcia-Martin ML, Grazu V, de la Fuente JM. Engineering biofunctional magnetic nanoparticles for biotechnological applications. Nano. 2010;2:1746-55.

38. Orlando A, Colombo M, Prosperi D, Corsi F, Panariti A, Rivolta I, Masserin M,Cazzaniga E. Evaluation of gold nanoparticles biocompatibility: a multiparametric study on cultured endothelial cells and macrophages. J Nanopart Res. 2016;18:58

39. Fu PP, Xia Q, Hwang HM, Ray PC, Yu H. Mechanisms of nanotoxicity: generation of reactive oxygen species. J Food Drug Anal. 2014;22:64-75.

40. Schlinkert P, Casals E, Boyles M, Tischler U, Hornig E, Tran N, Zhao J, Himly M, Riediker M, Oostingh GJ, et al. The oxidative potential of differently charged silver and gold nanoparticles on three human lung epithelial cell types. J Nanobiotechnology. 2015;13:1.

41. Le Bras M, Clement MV, Pervaiz S, Brenner C. Reactive oxygen species and the mitochondrial signaling pathway of cell death. Histol Histopathol. 2005; 20:205-19.

42. Arvizo RR, Moyano DF, Saha S, Thompson MA, Bhattacharya R, Rotello VM, Prakash YS, Mukherjee P. Probing novel roles of the mitochondrial uniporter in ovarian cancer cells using nanoparticles. J Biol Chem. 2013;288:17610-8.

43. Brenner C, Grimm S. The permeability transition pore complex in cancer cell death. Oncogene. 2006;25:4744-56.

44. Sumantran VN. Cellular chemosensitivity assays: an overview. Methods Mol Biol. 2011;731:219-36.

45. Yang C, Tian A, Li Z. Reversible cardiac hypertrophy induced by PEG-coated gold nanoparticles in mice. Sci Rep. 2016;6:20203.

46. Ajdary M, Ghahnavieh MZ, Naghsh N. Sub-chronic toxicity of gold nanoparticles in male mice. Adv Biomed Res. 2015;4:67.

47. Zhang XD, HY W, Wu D, Wang YY, Chang JH, Zhai ZB, Meng AM, Liu PX, Zhang LA, Fan FY. Toxicologic effects of gold nanoparticles in vivo by different administration routes. Int J Nanomedicine. 2010;5:771-81.

48. Jo M-R, Bae S-H, Go M-R, Kim H-J, Hwang Y-G, Choi S-J. Toxicity and biokinetics of colloidal gold nanoparticles. Nano. 2015;5:835-50.

49. Bhattarai SR, Derry PJ, Aziz K, Singh PK, Khoo AM, Chadha AS, Liopo A, Zubarev ER, Krishnan S. Gold nanotriangles: scale up and X-ray radiosensitization effects in mice. Nano. 2017:9:5085-93.

50. Paulsson M, Krag C, Frederiksen T, Brandbyge M. Conductance of alkanedithiol single-molecule junctions: a molecular dynamics study. Nano Lett. 2009;9:117-21.

51. Kruger D, Rousseau R, Fuchs H, Marx D. Towards "mechanochemistry": mechanically induced isomerizations of thiolate-gold clusters. Angew Chem Int Ed Engl. 2003:42:2251-3.

52. Darwish MA, Abo-Youssef AM, Khalaf MM, Abo-Saif AA, Saleh IG, Abdelghany TM. Vitamin E mitigates cisplatin-induced nephrotoxicity due to reversal of oxidative/nitrosative stress, suppression of inflammation and reduction of total renal platinum accumulation. J Biochem Mol Toxicol. 2017;31:1-9.

53. Kolosnjaj-Tabi J, Javed Y, Lartigue L, Volatron J, Elgrabli D, Marangon I, Pugliese G, Caron B, Figuerola A, Luciani N, et al. The one year fate of iron oxide coated gold nanoparticles in mice. ACS Nano. 2015;9:7925-39.

54. Sadauskas E, Danscher G, Stoltenberg M, Vogel U, Larsen A, Wallin H. Protracted elimination of gold nanoparticles from mouse liver. Nanomedicine. 2009:5:162-9.

55. Lao F, Chen L, Li W, Ge C, Qu Y, Sun Q, Zhao Y, Han D, Chen C. Fullerene nanoparticles selectively enter oxidation-damaged cerebral microvessel endothelial cells and inhibit JNK-related apoptosis. ACS Nano. 2009;3:3358-68.

56. Li JJ, Hartono D, Ong CN, Bay BH, Yung LY. Autophagy and oxidative stress associated with gold nanoparticles. Biomaterials. 2010;31:5996-6003.

57. Arvizo RR, Miranda OR, Thompson MA, Pabelick CM, Bhattacharya R, Robertson JD, Rotello VM, Prakash YS, Mukherjee P. Effect of nanoparticle surface charge at the plasma membrane and beyond. Nano Lett. 2010;10:2543-8.

58. Aporta A, Arbues A, Aguilo Jl, Monzon M, Badiola JJ, de Martino A, Ferrer N, Marinova D, Anel A, Martin C, Pardo J. Attenuated mycobacterium tuberculosis SO2 vaccine candidate is unable to induce cell death. PLoS One. 2012;7:e45213.

\section{Submit your next manuscript to BioMed Central and we will help you at every step:}

- We accept pre-submission inquiries

- Our selector tool helps you to find the most relevant journal

- We provide round the clock customer support

- Convenient online submission

- Thorough peer review

- Inclusion in PubMed and all major indexing services

- Maximum visibility for your research

Submit your manuscript at www.biomedcentral.com/submit 